\title{
Conductive Hearing Loss Has Long-Lasting Structural and Molecular Effects on Presynaptic and Postsynaptic Structures of Auditory Nerve Synapses in the Cochlear Nucleus
}

\author{
[CCheryl Clarkson, ${ }^{1}$ Flora M. Antunes, ${ }^{1}$ and Maria E. Rubio ${ }^{1,2,3}$ \\ Departments of ${ }^{1}$ Otolaryngology and ${ }^{2}$ Neurobiology and ${ }^{3}$ Center for the Neural Basis of Cognition, University of Pittsburgh, Pittsburgh, Pennsylvania 15261
}

Sound deprivation by conductive hearing loss increases hearing thresholds, but little is known about the response of the auditory brainstem during and after conductive hearing loss. Here, we show in young adult rats that $10 \mathrm{~d}$ of monaural conductive hearing loss (i.e., earplugging) leads to hearing deficits that persist after sound levels are restored. Hearing thresholds in response to clicks and frequencies higher than $8 \mathrm{kHz}$ remain increased after a $10 \mathrm{~d}$ recovery period. Neural output from the cochlear nucleus measured at $10 \mathrm{~dB}$ above threshold is reduced and followed by an overcompensation at the level of the lateral lemniscus. We assessed whether structural and molecular substrates at auditory nerve (endbulb of Held) synapses in the cochlear nucleus could explain these long-lasting changes in hearing processing. During earplugging, vGluT1 expression in the presynaptic terminal decreased and synaptic vesicles were smaller. Together, there was an increase in postsynaptic density (PSD) thickness and an upregulation of GluA3 AMPA receptor subunits on bushy cells. After earplug removal and a $10 \mathrm{~d}$ recovery period, the density of synaptic vesicles increased, vesicles were also larger, and the PSD of endbulb synapses was larger and thicker. The upregulation of the GluA3 AMPAR subunit observed during earplugging was maintained after the recovery period. This suggests that GluA3 plays a role in plasticity in the cochlear nucleus. Our study demonstrates that sound deprivation has long-lasting alterations on structural and molecular presynaptic and postsynaptic components at the level of the first auditory nerve synapse in the auditory brainstem.

Key words: 3D reconstructions; AMPA receptors; postembedding immunogold labeling; postsynaptic density; synaptic vesicles; vGluT1

Significance Statement

Despite being the second most prevalent form of hearing loss, conductive hearing loss and its effects on central synapses have received relatively little attention. Here, we show that $10 \mathrm{~d}$ of monaural conductive hearing loss leads to an increase in hearing thresholds, to an increased central gain upstream of the cochlear nucleus at the level of the lateral lemniscus, and to long-lasting presynaptic and postsynaptic structural and molecular effects at the endbulb of the Held synapse. Knowledge of the structural and molecular changes associated with decreased sensory experience, along with their potential reversibility, is important for the treatment of hearing deficits, such as hyperacusis and chronic otitis media with effusion, which is prevalent in young children with language acquisition or educational disabilities.

\section{Introduction}

Sensory experience regulates the structure and function of synapses in the central visual, somatosensory, and auditory systems.
Previous studies have revealed changes in synaptic morphology and transmission after monocular deprivation or eyelid suture (Maffei et al., 2004; Hofer et al., 2009; Coleman et al., 2010),
Received Jan. 15, 2016; revised Aug. 3, 2016; accepted Aug. 12, 2016.

Author contributions: M.E.R. designed research; C.C. performed research; C.C., F.M.A., and M.E.R. analyzed data; C.C., F.M.A., and M.E.R. wrote the paper.

This work was supported by a grant from the NIH (R01DC013048 to M.E.R.) and by internal funding from the Department of Otolaryngology, University of Pittsburgh Medical School (M.E.R.). We authors thank Drs. Karl Kandler and Laurence Trussell for helpful suggestions and critical reading of this manuscript. We also thank Naama Balass for editing this manuscript.
The authors declare no competing financial interests.

Correspondence should be addressed to Dr. Maria E. Rubio, Departments of Otolaryngology and Neurobiology, University of Pittsburgh Medical School, BST3 Building, 3501 Fifth Avenue \#10015, Pittsburgh, PA 15261. E-mail: mer@pitt.edu.

DOI:10.1523/JNEUROSCI.0226-16.2016

Copyright $\odot 2016$ the authors $\quad 0270-6474 / 16 / 3610214-14 \$ 15.00 / 0$ 
whisker removal or mechanical whisker manipulation (Allen et al., 2003; Bender et al., 2006; Li et al., 2009), sensorineural hearing loss in congenitally deaf animal models (Redd et al., 2000; Oleskevich and Walmsley, 2002; Lee et al., 2003; Ryugo et al., 2005), cochlear ablations (Gulley et al., 1977; Suneja et al., 1998; Asako et al., 2005; Rubio, 2006), or age-related hearing loss (Wang and Manis, 2005, 2006). More recently, it has become clear that other forms of hearing impairment associated with conductive hearing loss can also alter synaptic transmission in central auditory regions (Xu et al., 2007, 2010). However, despite being the second most prevalent form of hearing loss, conductive hearing loss and its effects on central synapses have received relatively little attention.

Several studies have shown that the effects of conductive hearing loss are age dependent (McGinn and Henry, 1975; Popescu and Polley, 2010; Takesian et al., 2012; Caras and Sanes, 2015). Evidence also exists that in the adult, conductive hearing loss can affect later auditory brainstem response (ABR) waves (Ferguson et al., 1998) and cochlear nucleus activity (Potashner et al., 1997; Tucci et al., 1999, 2001, 2002; Cook et al., 2002; Sumner et al., 2005), as well as upregulate AMPA glutamate receptor (AMPAR) subunits (Whiting et al., 2009; Wang et al., 2011). However, it is unknown whether the effects of conductive hearing loss are reversible. A small number of psychoacoustic studies have suggested plasticity in the adult human auditory system after transient conductive hearing loss, suggesting a gain control mechanism operating at the level of the auditory brainstem (Formby et al., 2003, 2007; Munro and Blount, 2009). These studies led us to investigate whether similar plasticity mechanisms occur in the mature auditory brainstem of the rat after transient conductive hearing loss. We investigated the structural and molecular changes at the auditory nerve synapse on bushy cells of the cochlear nucleus after conductive hearing loss by earplugging. We also monitored functional changes within the auditory brainstem with ABRs.

The auditory nerve ending in the anteroventral cochlear nucleus is a large glutamatergic calyx-type terminal (endbulb of Held) that surrounds the soma of bushy cells (Fig. 1A; Ryugo and Fekete, 1982; Rouiller et al., 1986). Endbulb synapses contain AMPAR subunits with rapid kinetics (GluA3 and GluA4; Wang et al., 1998; Gardner et al., 1999, 2001; Whiting et al., 2009). The slower GluA1 subunit is absent at mature endbulb synapses, and the GluA2 subunit, whose absence is associated with fast synapses, is expressed at very low levels (Wang et al., 1998; Gardner et al., 1999, 2001). Bushy cells are a major cell type in the anteroventral cochlear nucleus, and they enhance the temporal fine structure information that is present in the phase-locked pattern of auditory nerve spikes (Joris et al., 1994). The endbulb of Held is a critical gateway for auditory activity entering the brain; thus, structural and molecular alterations at the synapse could have widely reaching consequences for auditory processing.

In the current study, we show that $10 \mathrm{~d}$ of monaural conductive hearing loss by earplugging at postnatal day 30 (P30) leads to increased hearing thresholds as well as to long-lasting presynaptic and postsynaptic structural and molecular effects at the endbulb of the Held synapse. Noteworthy is that P30 past maturation of connectivity and synaptic elements in the cochlear nucleus. These results are unexpected considering the prevalent view that mature endbulb synapses are simple relay points, built for highfidelity and high-frequency synaptic transmission, and a minimal requirement for synaptic plasticity. Thus, knowledge of the structural and molecular changes associated with decreased sensory experience, along with their potential reversibility, is important for the treatment of hearing deficits, such as hyperacusis and chronic otitis media with effusion.

\section{Materials and Methods}

Animals. Twenty P30 male Sprague Dawley rats (Charles River Laboratories) were used in this study. Twelve rats were assigned to the earplugged group, and eight were assigned to the sham group. All the rats were tested for hearing thresholds at P30 before monaural earplugging or sham procedures (see below; Fig. 1B). Rat home cages were positioned in racks in the animal facility room such that both sham and experimental animals were exposed to the same ambient sound. All procedures were approved by the University of Pittsburgh, Division of Laboratory Animal Resources and complied with the NIH requirements for the humane care and use of laboratory rats.

Auditory brainstem responses and monaural earplugging. For ABR testing, we used the protocol described by Wang et al. (2011). Sound levels for clicks and pure tones were calibrated using a one-quarter-inch microphone (model PCB-378C01; PCB Piezotronics). The calibration microphone was interfaced with our close-field speaker [MF1-M; Tucker-Davis Technologies (TDT)] using a $2 \mathrm{~cm}$ plastic tube, which was placed in a sealed (soundisolated) syringe tube (the coupler). All connections between the speaker, tube, coupler, and microphone were airtight to avoid inaccurate calibration. Calibration was performed using the TDT program BioSigRZ. All calibrations and ABRs were conducted in a sound-attenuating cubicle (ENV022SV; Med Associates). All animals were tested under isoflurane anesthesia for hearing thresholds by recording ABRs to clicks and pure tones in a sound-attenuating cubicle. A heating pad was used to maintain a constant body temperature of $37^{\circ} \mathrm{C}$. Three register electrodes (an active, a reference, and a ground) were placed subcutaneously on the midline of the scalp $(+)$, on the cheek toward the ear (-), and on the hind leg (ground). The electrodes were connected to a four-channel low-impedance head stage (RA4 LI; TDT). Thresholds were measured for the ipsilateral ear before, during the $10 \mathrm{~d}$ of earplugging, and $10 \mathrm{~d}$ after earplug removal. ABR testing was conducted for the ipsilateral (plugged) side using an evoked potential workstation (RZ6-A-P1; TDT) and a close-field speaker (MF1-M; TDT). Sound stimuli signals were generated and analyzed using BioSigRZ software (TDT). Click stimuli lasted 0.1 and $5 \mathrm{~ms}$ for tone bursts at $4,16,24$, and $32 \mathrm{kHz}$, with a linear rise-fall time of $2.5 \mathrm{~ms}$ and no plateau. Evoked potentials were averaged over 1024 sweeps, and waveforms were filtered using a bandpass filter of 300-3000 Hz. ABR waveforms were recorded at decreasing intervals of $5 \mathrm{~dB}$ beginning with $80 \mathrm{~dB}$ for clicks and $100 \mathrm{~dB}$ for pure tones in the sham and earplugged rats. Auditory thresholds for clicks and pure tones were determined by blind visual inspection at the lowest intensity at which waves I and II were detectable above noise within a specified time window. The latency and amplitude (peak to peak) of click ABR waves were analyzed at 10 $\mathrm{dB}$ SPL above threshold. To determine changes in gain in response to transient earplugging, the average ratios of ABR wave II to I in the earplugged group were normalized by the average ratios from the age-matched sham group, within each age group (P30, P40, and P50; Fig. 1G). Similar calculations were performed to calculate the relative gain between waves IV and I at P30, P40, and P50 (Fig. 1G).

Earplugging and earplug removal. After the initial ABR testing at P30, the rats in the earplugged group $(n=12)$ were unilaterally earplugged for $10 \mathrm{~d}$ until they reached P40, and at that age, the earplug was removed in seven animals, which were then kept alive for another $10 \mathrm{~d}$ (P50; Fig. 1B). In the animals of the sham group, a surgical silk was passed around the acoustic meatus but was not tied off. After earplugging, earplug removal or sham procedure (Fig. $1 B$ ) rats were returned to their home cage in the animal facility. For the earplugging, earplug removal or sham procedure rats were anesthetized with isoflurane and placed on an isothermal pad.

For the monaural earplugging, a foam plug (Aearo Company) was then carefully placed into the right external canal at P30 (Fig. 1B), and the base of the pinna was closed with stitches. The sham and earplugged groups had ABRs recorded $20 \mathrm{~min}$ after the earplugging or sham procedures (data not shown). All animals were inspected daily. After $10 \mathrm{~d}$ of earplugging (P40), ABRs were again recorded (Fig. $1 B, C$ ), and the earplugs were removed from seven rats. After earplug removal, daily inspections of the external canal and the tympanic membrane were performed with a clinical otoscope to ensure that the ear canal was kept clean and the 
A

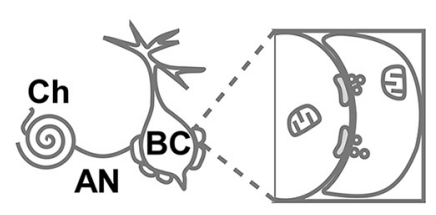

B

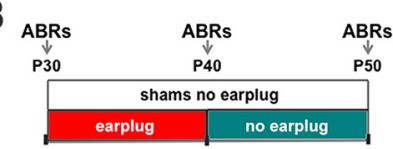

C
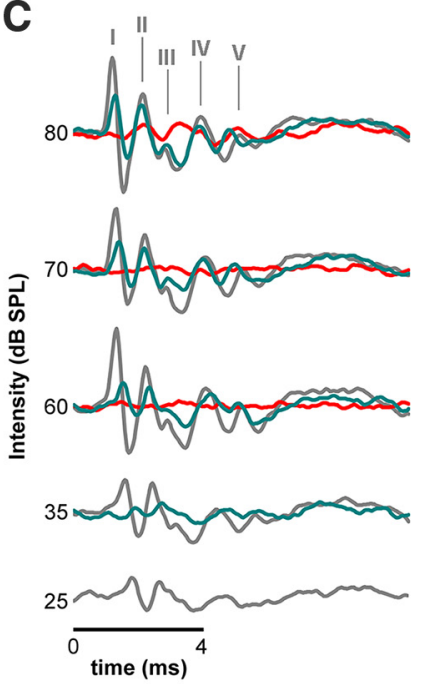

D

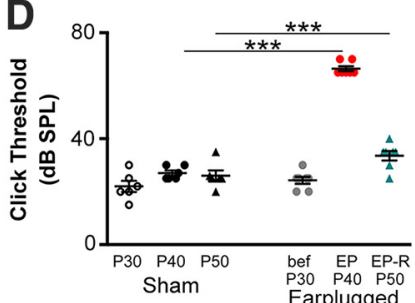

$E_{1}$
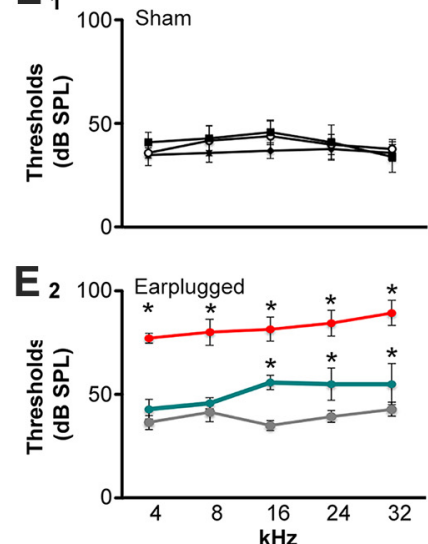

Before earplugging (bef; P30) - Earplug (EP; P40) Earplug-removal (EP-removal; P50)

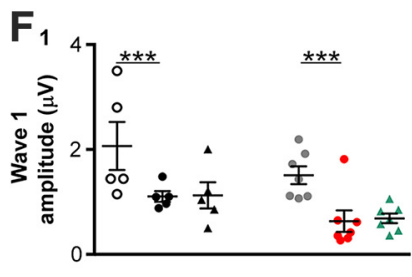

$F_{2}$
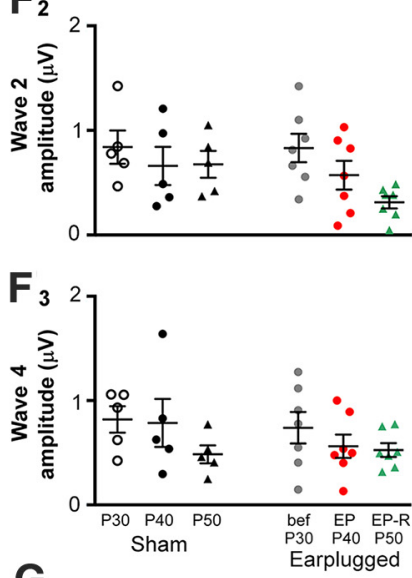

G

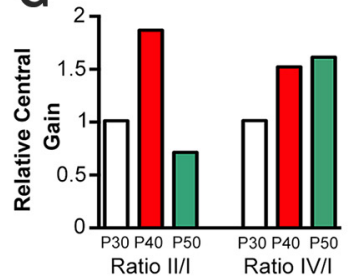

Figure 1. Scheme of the innervation of auditory nerve synapses on bushy cells and ABR recordings. $A$, Scheme of the innervation of the auditory nerve on bushy cells of the anteroventral cochlear nucleus. AN, Auditory nerve; $B C$, bushy cell; $C h$, cochlea. $B$, Diagram illustrating the experimental procedure. Animals were divided in two groups: shams and earplugged. Earplugged animals were recorded before earplugging (at P30), during earplugging (at P40, i.e., $10 \mathrm{~d}$ after earplugging), and after earplug removal (at P50). Shams were recorded at P30, P40, and P50 as age-matched controls without the earplug. C, Representative ABR waveforms from the same animal before earplugging (gray line), during earplugging (red line), and $10 \mathrm{~d}$ after earplug removal (green line) in the ipsilateral side. Waveform patterns between waves I and IV were similar before earplugging (EP) and after earplug removal. $\boldsymbol{D}$, Scatterplots of the ABR thresholds to clicks for the two animal groups (shams and earplugged) at the different ages tested (P30, P40, and P50). Means are displayed as error bars ( \pm SEM). Earplug significantly increased ABR thresholds during earplugging ( post hoc comparisons, Holm-Sidak method, within P40: earplugged vs sham, $t=17.80, p<0.001$ ). Earplugged animals did not recover to control levels $10 \mathrm{~d}$ after earplug removal (post hoc comparisons, Holm-Sidak method, within P50: earplugged vs sham, $t=3.42, p<0.001$ ). Asterisks indicate significance between earplugged animals and shams within the same age. $\boldsymbol{E}_{1}$, $\boldsymbol{E}_{2^{\prime}}$ Average population $A B R$ thresholds to the different frequencies tested $(4,16,24$, and $32 \mathrm{kHz})$ in shams $\left(\boldsymbol{E}_{1}\right)$ and earplugged animals $\left(\boldsymbol{E}_{2}\right)$. Earplugged animals significantly increased $A B R$ thresholds for each frequency during earplugging ( post hoc comparisons, Holm-Sidak method, within P40: earplugged vs sham; $4 \mathrm{kHz}: t=13.5, p<0.001 ; 8 \mathrm{kHz}: t=14.14, p<0.001 ; 16 \mathrm{kHz}: t=11.36$, $p<0.001 ; 24 \mathrm{kHz}: t=13.07, p<0.001 ; 32 \mathrm{kHz}: t=13.52, p<0.001$ ). Earplugged animals did not recover their hearing thresholds after earplug removal to frequencies higher than $16 \mathrm{kHz}$ (post hoc comparisons, Holm-Sidak method, within P50: earplugged vs sham; $16 \mathrm{kHz}: t=3.25, p<0.01 ; 24 \mathrm{kHz}: t=4.38, p<0.001 ; 32 \mathrm{kHz}: t=5.54, p<0.001$ ) but did recover their hearing thresholds in response to lower frequencies ( post hoc comparisons, Holm-Sidak method, within P50: earplugged vs sham; $4 \mathrm{kHz}: t=0.84, p=0.41 ; 8 \mathrm{kHz}: t=1.04, p=0.3_{1}$ ). Asterisk indicates significance between earplugged animals and shams within the same age. $\boldsymbol{F}_{1}-\boldsymbol{F}_{3}$, Scatterplots of the ABR wave $\left(\boldsymbol{F}_{1}\right)$, II $\left(\boldsymbol{F}_{2}\right)$, and IV $\left(\boldsymbol{F}_{3}\right)$ amplitudes measured at $10 \mathrm{~dB}$ SPL above threshold in the two animal groups for the three age levels. Earplugging had no significant effect on ABR amplitudes (2-way repeated-measures ANOVAs showed no significant interactions between age and animal group). Wave I amplitudes significantly decreased between P30 and P40 (post hoc comparisons, Holm-Sidak method, $t=4.45, p<0.001$ ), but this decrease can be attributed to the effect of age occurring in both animal groups independently of earplugging. $\mathbf{G}$, Relative central gain in earplugged animals. Wave ratios of the earplug groups (II/I and IV/I) were normalized by the wave ratios of the age-matched sham groups as described in Materials and Methods.

tympanic membrane was healthy. Any detritus that filled the plugged ear canal was removed. All animals included in the study had a normallooking external canal and tympanic membrane. Rats were retested at $10 \mathrm{~d}$ after earplug removal (P50; Fig. $1 B, C$ ). After the appropriate survival time, rats were transcardially perfused.

Tissue preparation for conventional transmission electron microscopy. To prepare the cochlear nucleus for transmission electron microscopy, we followed a protocol described by Deerinck et al. (2010). A total of eight rats ( $\operatorname{sham~} \mathrm{P} 40, n=2$; earplugged $\mathrm{P} 40, n=2$; sham P50, $n=2$; earplugremoval P50, $n=2$ ) were used. The animals were paired for all procedures with one sham and one experimental animal in each pair. Animals were deeply anesthetized with a ketamine/xylazine mix (60 and $6.5 \mathrm{mg}$ / $\mathrm{kg}$, respectively) and perfused through the heart with a fixative solution containing $2 \%$ paraformaldehyde and $2.5 \%$ glutaraldehyde in $0.15 \mathrm{M}$ cacodylate buffer, $\mathrm{pH} 7.4$, with $2 \mathrm{~mm}$ calcium chloride at room temperature. Brains were then removed and postfixed for $2 \mathrm{~h}$ in the same fixative solution at $4^{\circ} \mathrm{C}$. Coronal brainstem slices ( $80 \mu \mathrm{m}$ thick) were vibratome sectioned in an ice-cold solution $(0.15 \mathrm{~m}$ cacodylate buffer and $2 \mathrm{~mm}$ calcium chloride). Slices were washed with the same solution and incubated in a solution containing $3 \%$ potassium ferrocyanide in $0.3 \mathrm{M}$ cacodylate buffer with $4 \mathrm{~mm}$ calcium chloride and $4 \%$ aqueous osmium tetroxide. Tissues were washed with doubled distilled $\mathrm{H}_{2} \mathrm{O}\left(\mathrm{ddH}_{2} \mathrm{O}\right)$ and incubated in a filtered thiocarbohydrazide solution. After this incubation, sections were washed with $\mathrm{dd}_{2} \mathrm{O}$ and placed in a $2 \%$ osmium tetroxide solution in $d_{d d H_{2}} \mathrm{O}$. Sections were washed with $d_{d d H_{2}} \mathrm{O}$ and placed overnight in $1 \%$ uranyl acetate. Afterward, sections were stained en bloc using Walton's lead aspartate solution (Walton, 1979). After several washes in $\mathrm{ddH}_{2} \mathrm{O}$, sections were dehydrated in a series of ethanol 
rinses $(50,70,85,95$, and 100\%), infiltrated with epoxy resin (\#EMbed812; Electron Microscopy Science), and embedded between acetate sheets. Sections were placed in an oven at $60^{\circ} \mathrm{C}$ for $48 \mathrm{~h}$ for polymerization. Ultrathin sections for the analysis of postsynaptic density (PSD) length and thickness (see below) were counterstained with lead citrate to enhance the electron-dense material of the PSD.

$3 D$ reconstructions of serial ultrathin sections and morphometric analyses. After polymerization, the ipsilateral (right side) rostral anterior anteroventral cochlear nucleus of sham and experimental groups were trimmed and block-mounted. All blocks were obtained from similar core regions of the anteroventral cochlear nucleus. A series of 25 serial ultrathin sections $(60-70 \mathrm{~nm})$ was cut per block (two blocks per animal) with a Leica EM UC7 ultramicrotome and collected on formvar-coated, single-slot grids. Serial ultrathin sections were observed with a JEOL 1400 transmission electron microscope. Identification of auditory nerve (endbulb) synapses on bushy cell somata was completed following the criteria previously described by Gómez-Nieto and Rubio (2009) and Ryugo et al. (1997). Identified endbulb synapses on bushy cells were photographed at $60,000 \times$ magnification with a side-mounted CCD camera (GATAN). Image brightness and contrast were modified using Adobe Photoshop (Adobe Systems).

We used the Reconstruct software (http://synapses.clm.utexas.edu/ tools/reconstruct/reconstruct.stm; Fiala, 2005) to create 3D reconstructions of the PSD of 60 endbulb synapses on bushy cells $(n=15$ for each animal group). The electron micrographs for the $3 \mathrm{D}$ reconstructions were taken at $60,000 \times$.

Analysis of PSD thickness and synaptic vesicle size, volume, and density. In single images (at $60,000 \times$ magnification), in which the presynaptic membrane was parallel to the postsynaptic plasma membrane, the thickness of the PSDs ( $n=88,22$ for each animal group; see Fig. 4) was analyzed as described previously by Dosemeci et al. (2001) and Rubio (2006) using ImageJ software (rsbweb.nih.gov/ij/; see Fig. 4). An observer blinded to each animal group performed all measurements.

Using single TEM images, the density of synaptic vesicles (SVs) per endbulb profile was measured in a total of 252 terminals (sham P40, $n=$ 53; earplugged $\mathrm{P} 40, n=67$; sham P50, $n=65$; earplug-removal P50, $n=$ 67 ) at a magnification of $30,000 \times$, after plotting all of the SVs per endbulb terminal and calculating the endbulb ending area. Mitochondria within the axoplasm were not subtracted. The SV size was measured in a total of 9270 vesicles (for all animal groups). We manually delineated the outer profile of all SVs that exhibited both inner and outer membranes using Canvas software; for this analysis, we excluded SV caps or ghosts. To adjust for possible sectioning artifacts (Karunanithi et al., 2002), we made corrections to SV size by applying the correction formula described by Parsons et al. (1995). As shown in Figure 7A in the study by Parsons et al. (1995), we imagined a spherical synaptic vesicle of radio $R$ move through a section of thickness $h$ and plot the largest diameter of the synaptic vesicle profile captured by the section against the position of the synaptic vesicles' center. The average profile radius, $r$, is equal to the area under the curve divided by the horizontal distance between the extremes of the curve $\left[r=\left(\pi R^{2} / 2+\mathrm{Rh}\right) /(2 R+h)\right]$ as an estimate of the diameter of spherical structures. We also calculated the SV volume, as described by Karunanithi et al. (2002), using both the outer- and innerdiameter measurements (outer diameter minus twice the vesicle membrane thickness).

Freeze-substitution and postembedding immunogold labeling for vesicular glutamate transporter and AMPAR subunits. To determine the expression of vesicular glutamate transporter (vGluT1) in auditory nerve endings and AMPAR subunits (GluA2-4) at the PSDs of endbulb synapses on bushy cells in response to $10 \mathrm{~d}$ of earplugging and at $10 \mathrm{~d}$ after earplug removal, we used postembedding immunogold after freezesubstitution as described previously (Rubio and Wenthold, 1997, 1999; Whiting et al., 2009). Paired sham $(n=4)$ and earplugged $(n=6)$ animals were used for transcardial perfusions, tissue preparation, freezesubstitution, and postembedding immunogold labeling ( $\operatorname{sham~P40,n=}$ 2 rats; earplugged $\mathrm{P} 40, n=3$ rats; sham P50, $n=2$ rats; earplug-removal P50, $n=3$ rats). Briefly, brains were perfused with a low glutaraldehyde fixative containing $4 \%$ paraformaldehyde and $0.5 \%$ glutaraldehyde in $0.12 \mathrm{~m}$ phosphate buffer, $\mathrm{pH} 7.2$, for freeze-substitution. All brains were postfixed for $2 \mathrm{~h}$ in the same fixative solution at $4^{\circ} \mathrm{C}$, vibratome sectioned (150 $\mu \mathrm{m}$ thickness), and cryoprotected in glycerol. The rostral anteroventral cochlear nucleus was dissected, frozen by plunging into liquid propane, and processed first for freeze-substitution. For postembedding immunogold labeling for vGluT1 or AMPAR subunits, ultrathin sections ( $80 \mathrm{~nm}$ thickness) were processed using a protocol similar to that described by Rubio and Wenthold (1997) and Rubio et al. (2008). A polyclonal rabbit antibody for vGluT1 (RRID:AB_2617092; Synaptic Systems) was used at a 1:350 dilution. Affinity-purified C-terminus rabbit polyclonal antibodies for GluA2, GluA2/3, and GluA4 were gifts from Dr. Robert Wenthold (NIDCD-NIH, Bethesda, MD) and were used at a dilution of 1:100. Primary antibodies were recognized by anti-rabbit IgG gold-conjugated (10 nm in diameter) secondary antibodies (Ted Pella). Sections were counterstained with uranyl acetate and lead citrate.

We calculated the number of gold particles per PSD and the linear density of gold particles per PSD for GluA2/3, GluA2, and GluA4 in a total of 1804 endbulb synapses on bushy cells as described previously (Rubio and Wenthold, 1997; Rubio, 2006; Whiting et al., 2009). PSD length was measured using Canvas software, and the number of gold particles was manually counted. Additionally, the percentage of labeled and unlabeled PSDs was plotted in relation to the number of gold particles. The number and density of vGluT1 gold labeling was calculated in a total of 202 auditory nerve endings (sham P40, $n=42$; earplugged P40, $n=42$; sham P50, $n=52$; and earplug-removal P50, $n=68$ ). Only gold particles within the axoplasm of the auditory nerve ending were quantified. The number of gold particles per synaptic vesicle was calculated in 20 endbulb profiles per animal group by dividing the total number of gold particles per endbulb profile by the total number of synaptic vesicles per profile. The number and density of gold particles for AMPAR subunits and vGluT1 were not different among the animals analyzed for each of the groups [i.e., sham (P40 and P50), $10 \mathrm{~d}$ of earplugging (P40), or $10 \mathrm{~d}$ after earplug removal (P50)].

Statistical analyses. To analyze ABRs across conditions (sham vs earplugged) and age (P30, P40, and P50), two-way repeated-measures ANOVAs (one-factor repetition) were performed (factors, condition $X$ age; repeated factor, age). Data were tested for normality of distribution (Shapiro-Wilk test) and equality of variance (Brown-Forsythe test). If a significant interaction was observed, multiple comparisons (versus control group) were performed (Holm-Sidak method; control group for age, P30; control group for condition, sham). This analysis was performed for each ABR measurement (Amplitudes, Latencies, and Thresholds) and wave (wave I, II, and IV) separately. The purpose of this analysis was to understand whether there was an interaction between condition and age, which would indicate that the effect of different levels of condition (sham vs earplugged) depended on what level of age was present (P30, P40, or P50), i.e., whether there were differences in ABR responses across age depending on the presence or absence of the earplug. Since at P30 both groups are control groups, we do not expect to see a significant difference at this age level. We expect to see significant interactions between condition and age due to differences at P40 and/or P50 between shams and earplugged animals. A significant difference at P50 would indicate that ABRs were not recovered after earplug removal. For the ultrastructural analysis and postembedding immunogold labeling for vGluT1 and AMPA receptors, comparisons were performed using a Mann-Whitney $U$ test. All data are expressed as the means \pm SEM, and the level of significance was fixed at 0.05 for all comparisons. Statistical analyses were performed using SigmaPlot 13 (Systat Software) and Prism 5.0d software (GraphPad Software).

\section{Results}

\section{Monaural conductive hearing loss increases auditory brainstem response thresholds}

To evaluate whether earplugging had an effect on animal hearing thresholds, we measured ABR thresholds in response to clicks and pure tones in the two animal groups (sham vs earplugged) at three different ages (P30, P40, and P50; Fig. 1B). Earplugging significantly increased ABR thresholds for clicks by $43 \pm 1.50 \mathrm{~dB}$ SPL (two-way repeated-measures ANOVA: main effect of condition, $F_{(1,22)}=$ 
88.87, $p<0.001$; main effect of age, $F_{(2,22)}=210.99, p<0.001$; interaction, $F_{(2,22)}=144.17, p<0.001$; Fig. $\left.1 D\right)$. Post hoc comparisons (Holm-Sidak method) showed that the average ABR thresholds of earplugged animals during earplug were significantly higher than ABR thresholds of age-matched sham animals (i.e., P40: $t=$ 17.80, $p<0.001$; Fig. $1 D$ ). Moreover, the ABR thresholds of earplugged animals after earplug removal were significantly higher than ABR thresholds of age-matched sham animals (i.e., P50: $t=3.42$, $p<0.001$; Fig. $1 D$ ). Therefore, earplugged animals do not recover their ABR thresholds in response to clicks to the level of control animals after $10 \mathrm{~d}$ of earplug removal.

We next addressed how ABR thresholds in response to pure tones of different frequencies $(4,8,16,24$, and $32 \mathrm{kHz})$ were affected by earplugging. We analyzed the data with a two-way repeated-measures ANOVA for each frequency tested. There was a significant effect of earplugging on ABR thresholds in response to all frequencies ( $4 \mathrm{kHz}$ : main effect of condition, $F_{(1,22)}=47.86$, $p<0.001$; main effect of age, $F_{(2,22)}=66.35, p<0.001$; interaction, $F_{(2,22)}=73.84, p<0.001 ; 8 \mathrm{kHz}$ : main effect of condition, $F_{(1,22)}=42.87, p<0.001$; main effect of age, $F_{(2,22)}=210.52, p<$ 0.001 ; interaction, $F_{(2,22)}=152.25, p<0.001 ; 16 \mathrm{kHz}$ : main effect of condition, $F_{(1,22)}=35.81, p<0.001$; main effect of age, $F_{(2,22)}=112.22, p<0.001$; interaction, $F_{(2,22)}=63.56, p<0.001$; $24 \mathrm{kHz}$ : main effect of condition, $F_{(1,22)}=4.30, p<0.001$; main effect of age, $F_{(2,22)}=72.53, p<0.001$; interaction, $F_{(2,22)}=$ $62.29, p<0.001 ; 32 \mathrm{kHz}$ : main effect of condition, $F_{(1,22)}=86.52$, $p<0.001$; main effect of age, $F_{(2,22)}=68.52, p<0.001$; interaction, $F_{(2,22)}=54.12, p<0.001$; Fig. $\left.1 E_{1}, E_{2}\right)$. Post hoc comparisons (Holm-Sidak method) confirmed that the ABR thresholds for each frequency were significantly higher in earplugged animals during earplugging than in age-matched sham animals (i.e., P40; $4 \mathrm{kHz}: t=13.5, p<0.001 ; 8 \mathrm{kHz}: t=14.14, p<0.001 ; 16 \mathrm{kHz}:$ $t=11.36, p<0.001 ; 24 \mathrm{kHz}: t=13.07, p<0.001 ; 32 \mathrm{kHz}: t=$ $13.52, p<0.001$; Fig. $\left.1 E_{1}, E_{2}\right)$. After earplug removal, the same analysis showed no significant differences in ABR thresholds between earplugged animals and shams at P50 in response to low frequencies ( $4 \mathrm{kHz}: t=0.84, p=0.41 ; 8 \mathrm{kHz}: t=1.04, p=0.31$; Fig. $\left.1 E_{1}, E_{2}\right)$. However, ABR thresholds in response to the middle and high frequencies were significantly different between earplugged and sham animals at P50 (16 kHz: $t=3.25, p<0.01 ; 24$ $\mathrm{kHz}: t=4.38, p<0.001 ; 32 \mathrm{kHz}: t=5.54, p<0.001$; Fig. $\left.1 E_{1}, E_{2}\right)$. In summary, these data indicate that earplugged animals did not recover their hearing thresholds after earplug removal in response to clicks and frequencies higher than $8 \mathrm{kHz}$ but did recover their hearing thresholds in response to lower frequencies (4 and $8 \mathrm{kHz}$ ). After earplug removal, the external canal was clean and the tympanic membrane appeared healthy; nevertheless, the persistence of higher-frequency thresholds suggests either the existence of sensorineural hearing loss or middle ear problems (e.g., increased ossicular chain stiffness) as secondary effects of conductive hearing loss.

To evaluate how earplugging affected ABR amplitudes, we measured wave I, II, and IV amplitudes (peak to peak) at $10 \mathrm{~dB}$ SPL above threshold in both animal groups at the three ages (Fig. $1 F_{1}-F_{3}$ ). This analysis showed no significant effects of condition and age on ABR amplitudes for all waves, except wave I. Although significant effects were found for wave I amplitudes, no significant interaction was present (two-way repeated-measures ANOVA: main effect of condition, $F_{(1,20)}=5.23, p=0.045$; main effect of age, $F_{(2,20)}=12.72, p<$ 0.001 ; interaction, $\left.F_{(2,20)}=0.04, p=0.96\right)$. Wave I amplitudes $10 \mathrm{~dB}$ above threshold significantly decreased between P30 and P40 (post hoc comparisons, Holm-Sidak method, $t=$
Table 1. ABR latency values

\begin{tabular}{llll}
\hline & Peak I & Peak II & Peak IV \\
\hline Sham group & & & \\
P30 & $1.60 \pm 0.01$ & $2.63 \pm 0.08$ & $4.43 \pm 0.06$ \\
P40 & $1.54 \pm 0.01$ & $2.32 \pm 0.02$ & $4.24 \pm 0.06$ \\
P50 & $1.56 \pm 0.02$ & $2.37 \pm 0.03$ & $4.21 \pm 0.07$ \\
Earplugged group & & & \\
$\quad$ Before earplugging (P30) & $1.60 \pm 0.02$ & $2.53 \pm 0.07$ & $4.56 \pm 0.10$ \\
$\quad$ Earplug (P40) & $1.99 \pm 0.06$ & $3.10 \pm 0.10$ & $4.62 \pm 0.08$ \\
Earplug-removal (P50) & $1.55 \pm 0.03$ & $2.45 \pm 0.06$ & $4.21 \pm 0.07$ \\
\hline
\end{tabular}

Data are in milliseconds.

4.45, $p<0.001$ ), but this decrease occurs in parallel between the two animal groups and is attributable to the effect of age. A reduction in wave I amplitude has been used as a measure to quantify degeneration in auditory nerve fibers (Shaheen et al., 2015). After earplug removal at P50 wave I amplitude was similar to the age-matched shams, this indicates that earplugging does not result in any measurable cochlear or auditory nerve degeneration. In summary, earplugging had no effect in ABR wave (I, II, and IV) amplitudes measured at $10 \mathrm{~dB}$ SPL above threshold.

We finally addressed whether earplugging changed ABR wave (I, II, and IV) latencies at $10 \mathrm{~dB}$ SPL above threshold (Table 1). We analyzed the data with a two-way repeated-measures ANOVA for each wave (I, II, and IV). This analysis showed a significant interaction between age and condition for waves I and II except wave IV (wave I: $F_{(2,20)}=30.73, p<0.001$; wave II: $F_{(2,20)}=19.42, p<0.001$; wave IV: $\left.F_{(2,20)}=2.39, p=0.117\right)$. Post hoc comparisons of the interactions showed a significant increase in latency in the earplugged animals at P40 compared with agedmatched shams for waves I and II (Holm-Sidak method; wave I: $t=7.71, p<0.001$; wave II: $t=6.79, p<0.001)$. No differences were found between the two animal groups at P50, indicating that after earplug removal, the animals recover their $\mathrm{ABR}$ latencies to the level of control animals.

\section{Monaural conductive hearing loss leads to an increase in the central gain upstream of the cochlear nucleus at the level of the lateral lemniscus}

To determine changes in gain (Schaette and McAlpine, 2011) in response to earplugging, the wave ratios of the earplug groups (II/I and IV/I) were normalized by the wave ratios of the agematched sham group (see Materials and Methods; Fig. 1G). As expected, no changes in gain were observed in the earplug group at P30, since at this age these animals are also controls (relative gain of 1). During earplugging (P40), the relative gain of earplugged animals increased by 86 and $52 \%$ in the average wave II/I and IV/I ratios, respectively. After earplugged removal (P50), the relative gain decreased by $29 \%$ in the wave II/I ratio while it increased by $61 \%$ in the wave IV/I ratio. These results suggest that earplugging leads to a gain increase in both the cochlear nucleus and the lateral lemniscus. On the other hand, once sound levels restore after earplugging removal, the gain increase only persists in the lateral lemniscus that is an auditory brainstem nucleus upstream of the cochlear nucleus.

\section{Presynaptic effects of monaural conductive hearing loss at auditory nerve endings}

Next, we investigated the molecular and structural changes at endbulb synapses that could explain the functional deficits we detected with ABRs. vGluT1 is the main glutamate vesicular 
A

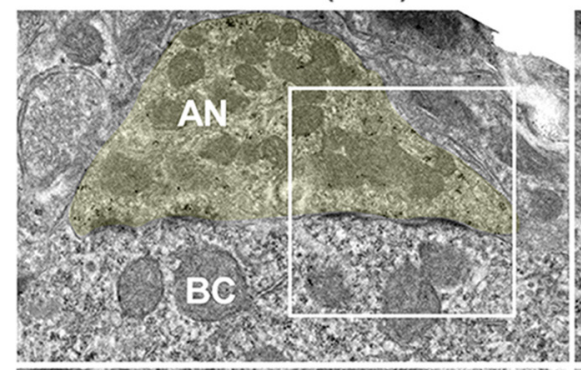

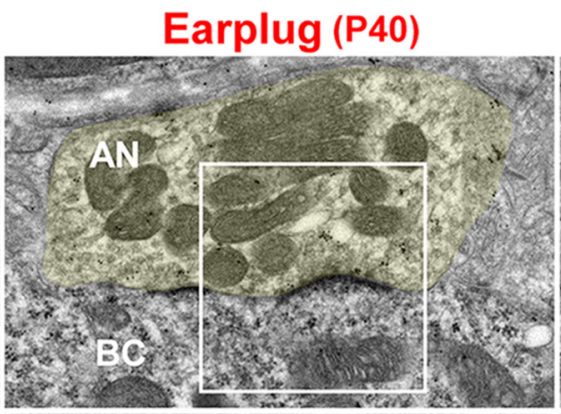
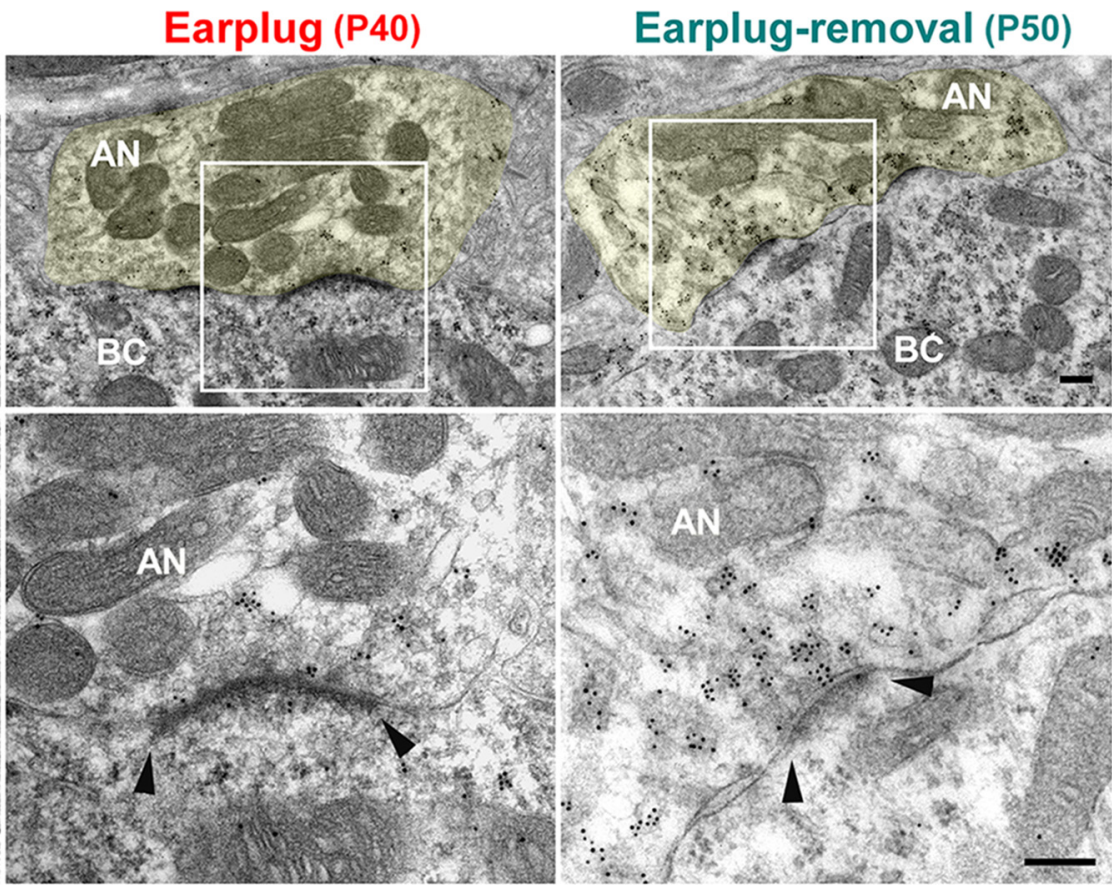

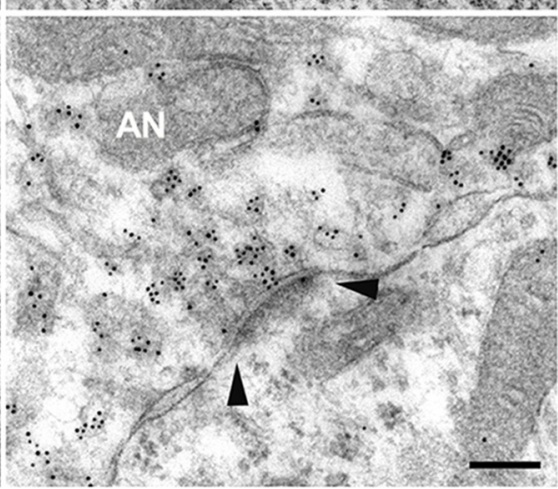

B
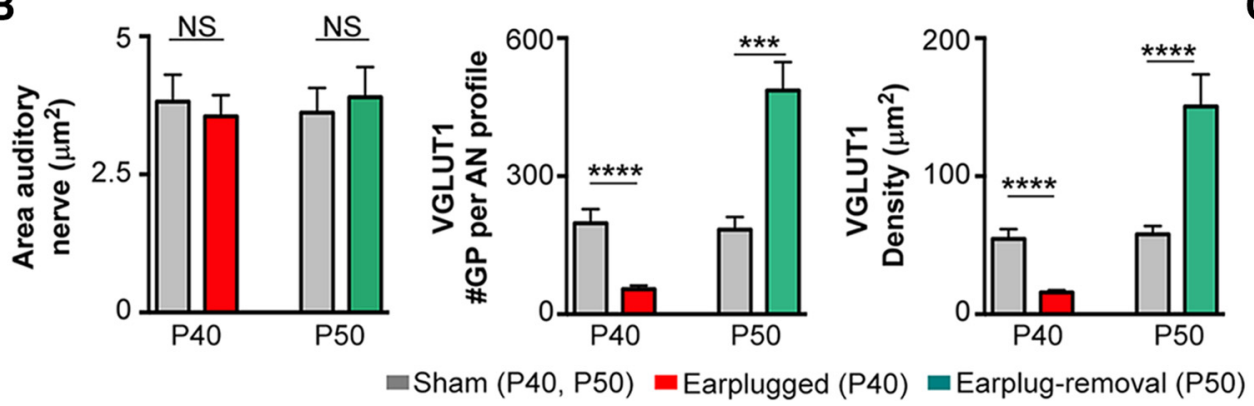

C

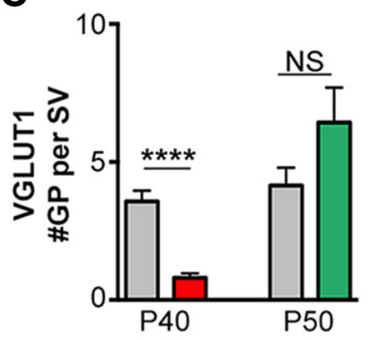

Figure 2. Monaural conductive hearing loss decreases vGluT1 expression within the cytoplasm of auditory nerve endings, and vGluT1 expression increases after earplug removal. A, Top row, Examples of auditory nerve endings on bushy cells immunolabeled with vGluT1 (10-nm-diameter gold particles) at low magnification. White boxed areas are magnified on the bottom row. Arrowheads note the edge of the PSD. AN, Auditory nerve; BC, bushy cell. Scale bars: top row, $250 \mathrm{~nm}$; bottom row, $200 \mathrm{~nm}$. B, Summary of the mean area of auditory nerve endings and number and density of gold particles for vGluT1 per auditory nerve ending. Areas of endbulb profiles were the same between the earplugged group and the age-matched P40 shams ( $p>0.05$, Mann-Whitney U test). vGluT1 gold labeling was significantly decreased in the earplugged animals compared with age-matched shams (number: P40 sham, 197.6 $\pm 30.57 ; \mathrm{P} 40 \mathrm{EP}, 54.4 \pm 7.91$; $* * * * p<0.0001$; density: P40 sham, $54.51 \pm 7.10 ;$ P40 EP, $15.68 \pm 1.7 ;{ }^{* * * *} p<0.0001$, Mann-Whitney $U$ test). Density and gold labeling for vGluT1 after earplug removal was higher than age-matched shams (number: P50 sham, $183.6 \pm 27.45 ;$ P50 EP-removal, $486.2 \pm 61.75 ;{ }^{* * *} p<0.003$; density: P50 sham, $57.95 \pm 5.93$; EP-removal, $150 \pm 23.4$; ${ }^{* * * *} p<0.001$, Mann-Whitney U test). Number and density of vGluT1 labeling was the same in P40 and P50 shams ( $p>0.05$, Mann-Whitney $U$ test). $C$, Average number of vGluT1 gold particles per SV in sham and earplugged animal groups. The number of gold particles per SV was significantly decreased in the earplugged animals compared with age-matched shams $\left(^{* * * *} p<0.0001\right.$, Mann-Whitney $U$ test). No difference was found in the number of vGluT1 gold particles per SV after earplugged removal compared with age-matched shams ( $p=0.20$, Mann-Whitney $U$ test). The difference between earplugged animals and age-matched controls was not found statistically significant ( $p>0.05$, Mann-Whitney $U$ test test).

transported at the endbulb terminals (Zhou et al., 2007; GómezNieto and Rubio, 2009; Fyk-Kolodziej et al., 2011), and vGluT1 expression levels could reflect how much glutamate is released to the synaptic cleft (Erickson et al., 2006; Liguz-Lecznar and Skangiel-Kramska, 2007). In the cochlear nucleus of deafened animals, the expression levels of vGluT1 at endbulb terminals are decreased compared with nondeafened animals (Zeng et al., 2009; Fyk-Kolodziej et al., 2011). We hypothesized that vGluT1 expression at the endbulb would decrease in response to $10 \mathrm{~d}$ of monaural conductive hearing loss. Postembedding immunolabeling for vGluT1 showed gold particles distributed within the axoplasm of endbulb terminals of shams, earplugged and after earplugged removal (Fig. 2). As expected, some gold particles for vGluT1 were also observed within the cytoplasm of bushy cells (Ito et al., 2011). Quantitative analysis of vGluT1 labeling within the axoplasm of endbulb endings showed a significant decrease
$(63 \%)$ in the average number and density of vGluT1 gold labeling in the earplugged group compared with age-matched $\mathrm{P} 40$ shams (number: $U=40.50, p<0.0001$, Mann-Whitney $U$ test; density: $U=12, p<0.0001$, Mann-Whitney $U$ test; Fig. $2 B)$. The number of vGluT1 gold particles per SV was also significantly decreased in the earplugged animals $(n=0.8$ gold particles) compared with age-matched shams $(n=3.5$ gold particles; $U=13, p<0.0001$, Mann-Whitney $U$ test; Fig. 2C). The ultrastructural morphometric analysis of the endbulb terminal profiles and SVs showed that the area of endbulb profiles and the average density of SVs within the terminal of earplugged animals were similar to age-matched shams (area: $U=193, p>0.05$, Mann-Whitney $U$ test; Fig. $2 B$, Table 2; density: $U=1681, p=0.7$, Mann-Whitney $U$ test; Fig. $3 B$ ). Interestingly, we found that SVs within the endbulb profiles of the earplugged group were significantly smaller in size (9.26\%) and volume (11.81\%) compared with the age-matched sham group (size: $U=$ 
Table 2. Area of AN and SV measurements of sham and earplugged animals

\begin{tabular}{|c|c|c|c|c|}
\hline & Sham (P40) & EP (P40) & Sham (P50) & EP-removal (P50) \\
\hline \multicolumn{5}{|l|}{ Area AN endings } \\
\hline Total & 53 & 67 & 65 & 67 \\
\hline Average area $\left(\mu \mathrm{m}^{2} ; \pm\right.$ SEM $)$ & $2.74 \pm 0.24$ & $2.25 \pm 0.17$ & $2.6 \pm 0.3$ & $2.68 \pm 0.47$ \\
\hline Median & 2.43 & 2.07 & 2.2 & 2.05 \\
\hline CV & 0.63 & 0.60 & 0.7 & 1.44 \\
\hline \multicolumn{5}{|l|}{ SVs } \\
\hline Average $n$ per $\mu \mathrm{m}^{2}$ ( \pm SEM) & $35.39 \pm 1.90$ & $37.68 \pm 3.19$ & $34.16 \pm 1.86$ & $63.19 \pm 4.26$ \\
\hline Median & 31.74 & 35.73 & 31.87 & 59.2 \\
\hline $\mathrm{CV}$ & 0.39 & 0.68 & 0.44 & 0.55 \\
\hline Average size (nm; \pm SEM) & $38.84 \pm 0.25$ & $35.84 \pm 0.08$ & $38.56 \pm 0.12$ & $46.66 \pm 0.15$ \\
\hline Median size & 38.66 & 35.65 & 38.57 & 46.70 \\
\hline CV & 0.11 & 0.13 & 0.01 & 0.11 \\
\hline Average volume (ZL; \pm SEM) & $43.94 \pm 0.25$ & $32.29 \pm 0.20$ & $43.22 \pm 0.23$ & $54.19 \pm 0.57$ \\
\hline Median volume & 40.79 & 29.29 & 40.77 & 53.32 \\
\hline CV & 0.41 & 0.46 & 0.36 & 0.35 \\
\hline
\end{tabular}

AN, Auditory nerve; CV, coefficient of variation.

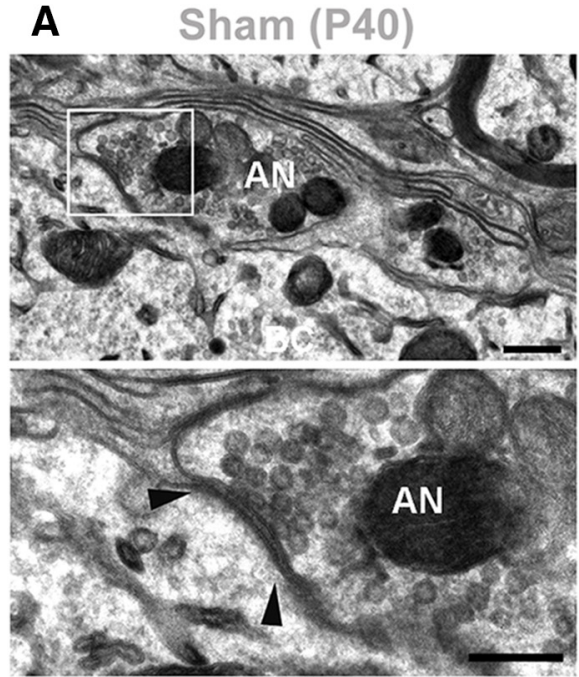

B

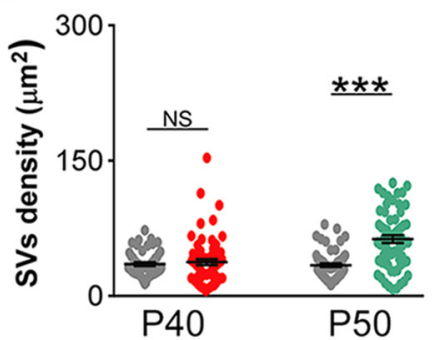

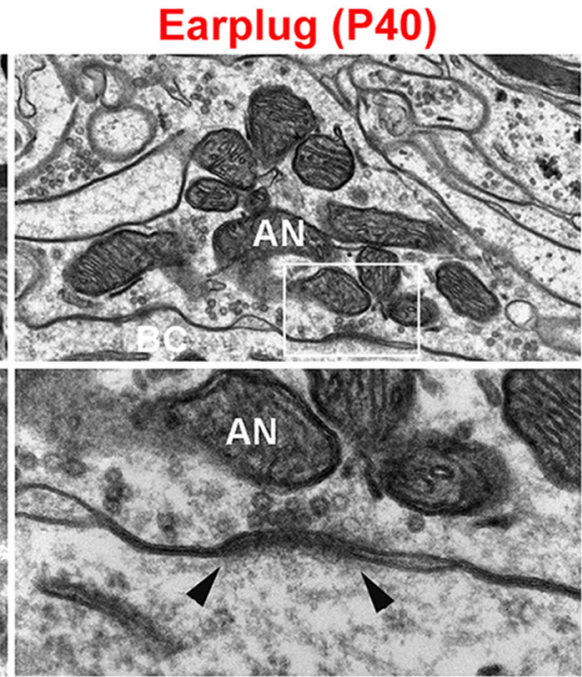

C

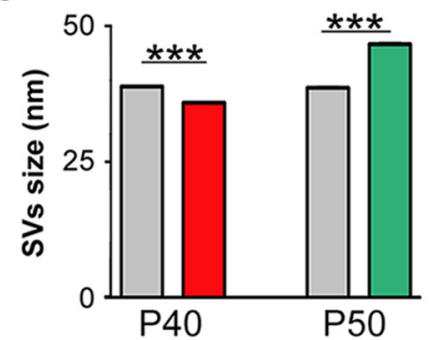

Eaplug-removal (P50)
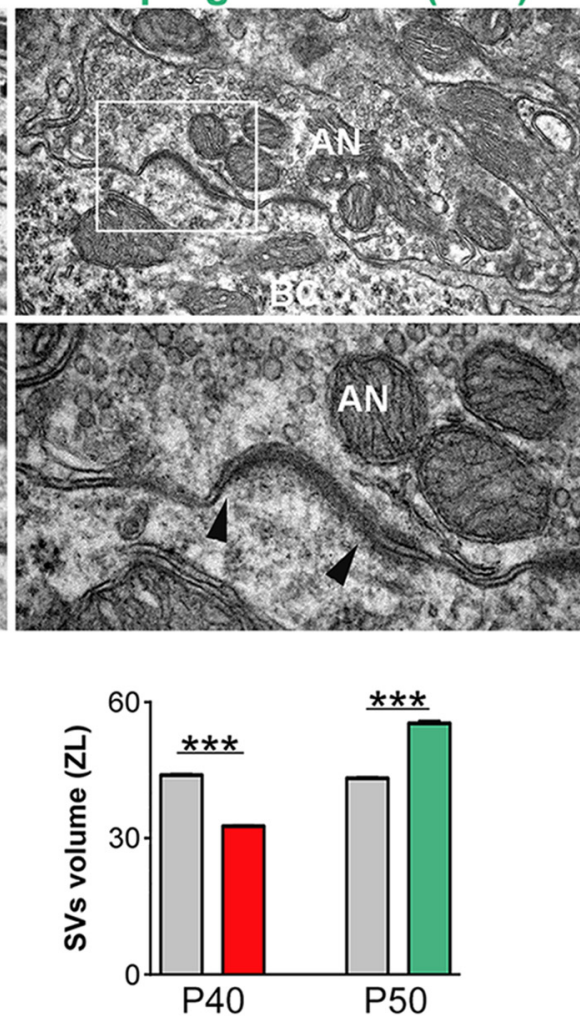

Figure 3. Changes in SV density, size, and volume in response to monaural conductive hearing loss. A, Electron micrographs of auditory nerve synapses on bushy cells of sham (P40), earplugged (P40), and postearplug-removal (P50) groups. White boxed areas are shown at higher magnification on the bottom row. Arrowheads note the edge of the PSD. AN, Auditory nerve; BC, bushy cell. Scale bars: top row, $250 \mathrm{~nm}$; bottom row, $200 \mathrm{~nm}$. B, Plot of the density of SVs per square micrometer of auditory nerve endings. SV density was similar in age-matched shams and earplugged animals $(p=0.07$, Mann-Whitney $U$ test) but was significantly increased in the earplug-removal group compared with age-matched shams $(p<0.0001$, Mann-Whitney $U$ test). Error bars are $\pm S E M$. C, The mean SV size was significantly lower in the earplugged animals compared with age-matched shams (*** $p<0.0001$, Mann-Whitney $U$ test), but it was significantly higher in the earplug-removal group compared with age-matched shams ${ }^{* * *} p<0.0001$, Mann-Whitney $U$ test). Error bars are \pm SEM. The mean $S V$ volume was significantly lower in the earplugged animals compared with age-matched shams $\left({ }^{* * *} p<0.0001\right.$, Mann-Whitney $U$ test), but it was significantly higher in the earplug-removal group compared with age-matched shams ${ }^{* * *} p<0.0001$, Mann-Whitney $U$ test). Error bars are \pm SEM.

396e $+006, p<0.0001$, Mann-Whitney $U$ test; volume: $U=$ 3.447e $+006, p<0.0001$, Mann-Whitney $U$ test; Fig. 3C, Table 2). Thus, the smaller SVs and lower levels of vGluT1 labeling at endbulb endings suggest that conductive hearing loss reduces the number of glutamate molecules per SV, and this could lead to a decrease in vesicular glutamate uptake and release.
Ten days after earplug removal, data showed a significant increase of $145 \%$ in the average number and density of vGluT 1 gold labeling in the earplug-removal group compared with agematched P50 shams (number: $U=37, p<0.003$, Mann-Whitney $U$ test; density: $U=26, p<0.0001$, Mann-Whitney $U$ test; Fig. $2 B$ ). The area of the endbulb terminal profiles was similar 
A

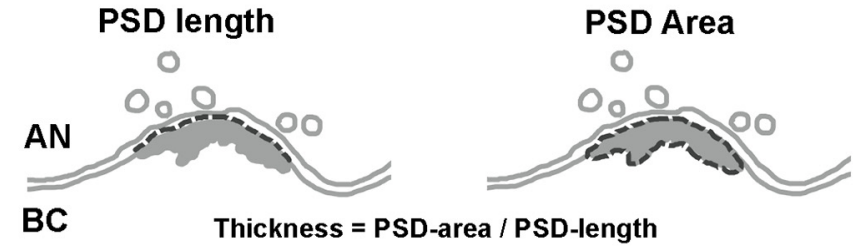

B

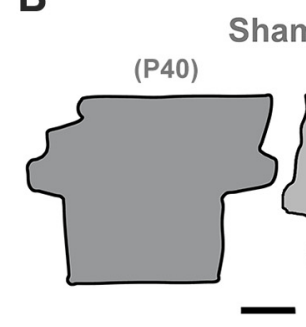

Sham

Thickness $=$ PSD-area $/$ PSD-length

C

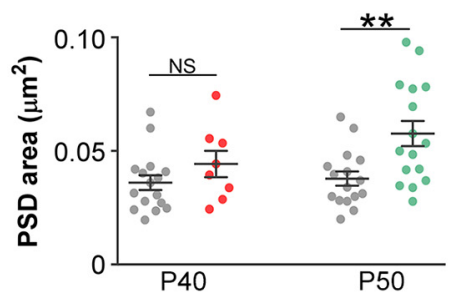

Earplug (P40) (P50)

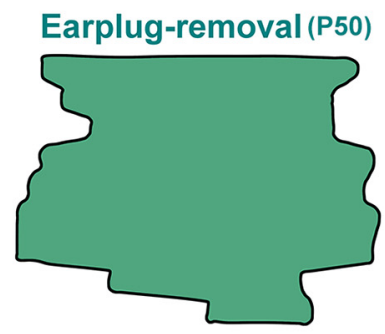

D

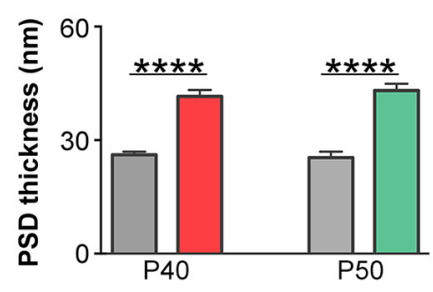

Figure 4. Monaural conductive hearing loss enlarges the postsynaptic membrane of auditory nerve synapses on bushy cells. $\boldsymbol{A}$, Drawings of an auditory nerve (AN) synapse on a bushy cell (BC) showing how the thickness of the PSD was calculated. $\boldsymbol{B}$, Representative PSD diagrams of the sham, earplug, and postearplug-removal groups that were obtained from the 3D reconstructions of serial ultrathin sections. Scale bar, $50 \mathrm{~nm}$. C, Plot showing a significant increase in the mean PSD area of the synapse of the auditory nerve on bushy cells after earplug removal (sham P40, $0.036 \pm 0.003 \mu \mathrm{m}^{2}$; earplugged P40, $0.045 \pm 0.005 \mu \mathrm{m}^{2}$; ${ }^{* *} p=0.02$, Mann-Whitney $U$ test; sham P50, $0.037 \pm 0.004 \mu \mathrm{m}^{2}$; earplug-removal P50, $0.058 \pm 0.005 \mu \mathrm{m}^{2} ; p=0.0006$, Mann-Whitney $U$ test). Error bars are \pm SEM. $D$, Plot showing a significant increase in the average PSD thickness during earplug and after $10 \mathrm{~d}$ of earplug removal (sham P40, $26.21 \pm 0.88 \mathrm{~nm}$; earplugged P40, $41.72 \pm 1.72 \mathrm{~nm}$; ${ }^{* * * *} p<0.0001$, MannWhitney $U$ test; sham P50, $25.47 \pm 1.56 \mathrm{~nm}$; earplug-removal P50, $43.28 \pm 1.793 \mathrm{~nm}$; ${ }^{* * *} p<0.0001$, Mann-Whitney U test). Error bars are \pm SEM.

between the earplug-removal and age-matched sham animals at P50 $(U=143, p=0.99$, Mann-Whitney $U$ test; Fig. $2 B)$, but we found an increase in SV size and density at endbulb terminals in the earplug-removal group compared with the age-matched sham group (size: $U=57,740 ; p<0.0001$, Mann-Whitney $U$ test; SV density: $U=1003, p<0.0001$, Mann-Whitney $U$ test; Fig. 3, Table 2). The number of gold particles per SV was similar between the earplug-removal animals ( $n=6.4$ gold particles) and age-matched shams $(n=4.1$ gold particles; $U=139, p=0.2$, Mann-Whitney $U$ test; Fig. $2 C$ ). Thus, the higher labeling of vGluT1 at endbulb terminals after earplug removal is explained by the increase in SV number.

\section{Monaural conductive hearing loss enlarges the postsynaptic density of the endbulb synapse}

The structure and composition of the PSD are modified by external stimuli and by synaptic activity over the time course of seconds to minutes and hours to days (Sheng and Hoogenraad, 2007). Thus, we examined the effect of transient monaural hearing loss on the area and thickness of the PSD of endbulb synapses on bushy cells (Fig. 4). Data from the earplugged animals at P40 compared with agematched shams showed a $60 \%$ increase in PSD thickness $(U=12$, $p<0.0001$, Mann-Whitney $U$ test). After earplug removal at P50 and when compared with age-matched shams, the PSDs were significantly larger and thicker by 59 and $65 \%$, respectively (area: $U=57$, $p=0.006$; thickness: $U=6, p<0.0001$; Mann-Whitney $U$ test; Fig.

4). No significant change in PSD area or thickness was observed between P40 and P50 shams (area: $U=113, p=0.58$; thickness: $U=91, p=0.65$; Mann-Whitney $U$ test; Fig. 4). These results indicate that conductive hearing loss induces a long-term enlargement of the PSD at endbulb synapses on bushy cells.

\section{AMPAR scaling at the auditory nerve synapse on bushy cells in response to monaural conductive hearing loss involves the GluA3 subunits}

Activity-dependent trafficking of AMPARs is a key mechanism underlying the strengthening and plasticity of glutamatergic synapses (Bredt and Nicoll, 2003; Collingridge et al., 2004). AMPARs are tetrameric complexes composed of homologous or heterologous combinations of GluA1-4 subunits. As different subunit compositions determine the electrophysiological properties of the AMPAR channel (Hollmann and Heinemann, 1994), it is critical to determine the long-term effects of conductive hearing loss on the expression of AMPAR subunits at the endbulb synapse on bushy cells (Fig. 5).

We first analyzed whether conductive hearing loss altered the percentage of the total pool of gold-labeled PSDs of endbulb synapses. In the P40 sham group, we found that $80.6 \%$ of the PSDs were gold labeled for GluA2/3, whereas only 43 and $39.3 \%$ of the PSDs were labeled for GluA2 or GluA4, respectively. After $10 \mathrm{~d}$ of earplugging (P40), the percentage of PSDs labeled for GluA2/3, GluA2, or GluA4 was similar to age-matched shams $(p>0.5$, Mann-Whitney $U$ test; Fig. $5 B$ ). Second, we determined the number and density of gold particles labeled for GluA2/3, GluA2, and GluA4 at the PSDs of endbulb synapses (Fig. $5 C$ ). This analysis revealed that GluA2/3 was upregulated in the earplugged animals compared with age-matched shams (number: $U=9454, p=0.01$, Mann-Whitney $U$ test; density: $U=9423, p=0.0122$, MannWhitney $U$ test). On the other hand, the values for GluA2 and GluA4 were not different from those of the age-matched sham group (GluA2, number: $U=6124, p=0.75$, Mann-Whitney $U$ test; density: $U=5406, p=0.44$, Mann-Whitney $U$ test; GluA4, number: $p=0.1690$, Mann-Whitney $U$ test; density: $p=0.1603$, Mann-Whitney $U$ test). These measurements indicate that the GluA3 subunit, which is an AMPAR subunit with rapid kinetics (Gardner et al., 1999), was increased at endbulb synapses in response to conductive hearing loss. This increase could represent a homeostatic compensatory mechanism in response to sound reduction.

Similar analyses were performed for earplugged animals at P50 (i.e., $10 \mathrm{~d}$ after earplug removal) and aged-matched shams (Fig. 6). In the P50 sham group, 70\% of the PSDs were gold labeled for GluA2/3, whereas only $45 \%$ were labeled for GluA2 or GluA4. In the P50 earplugged group, the percentage of PSDs labeled for GluA2/3, GluA2, or GluA4 was similar to agematched shams ( $p>0.5$, Mann-Whitney $U$ test; Fig. $6 B)$. The 
A
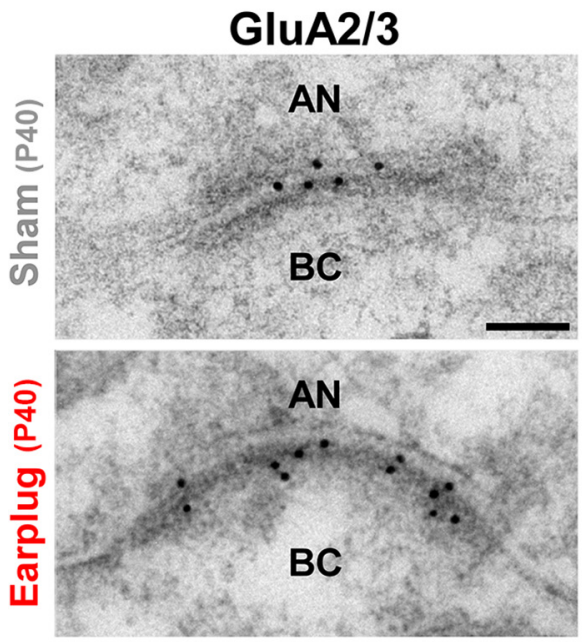

B

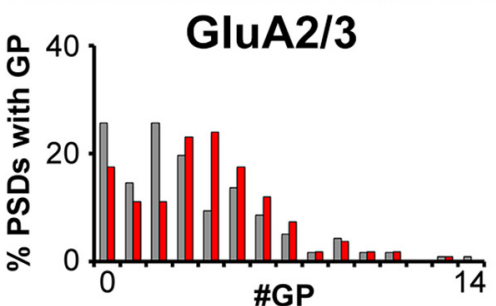

C
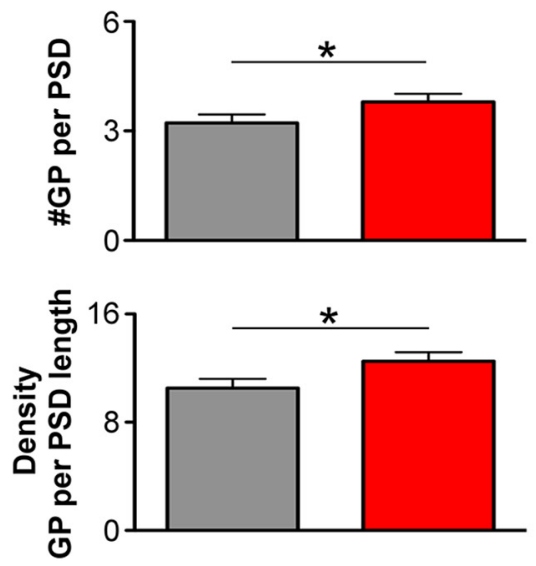

GluA2

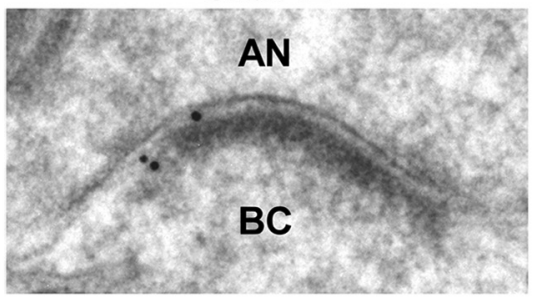

AN
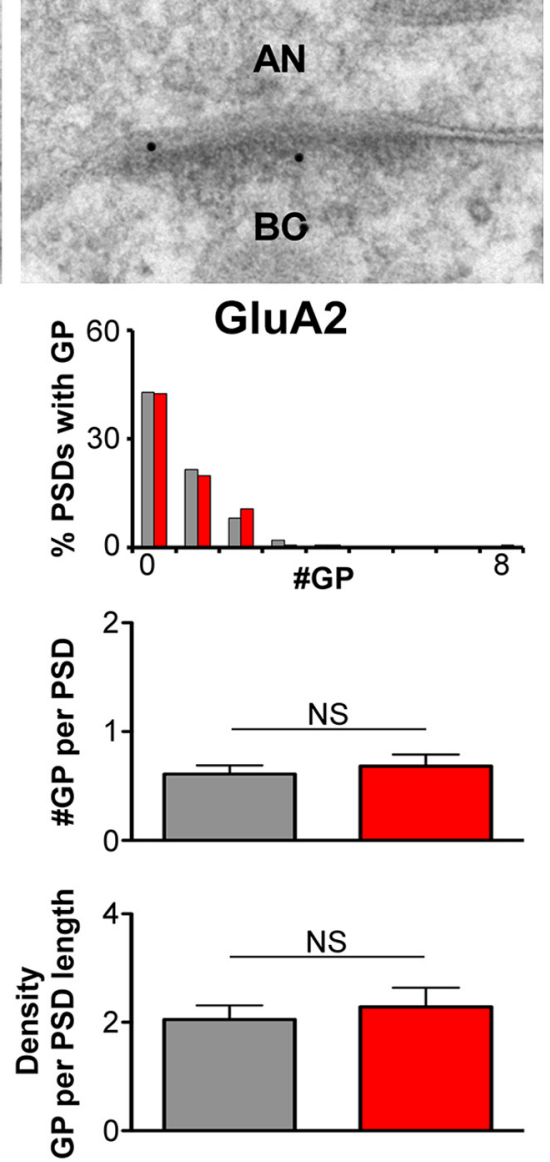

GluA4
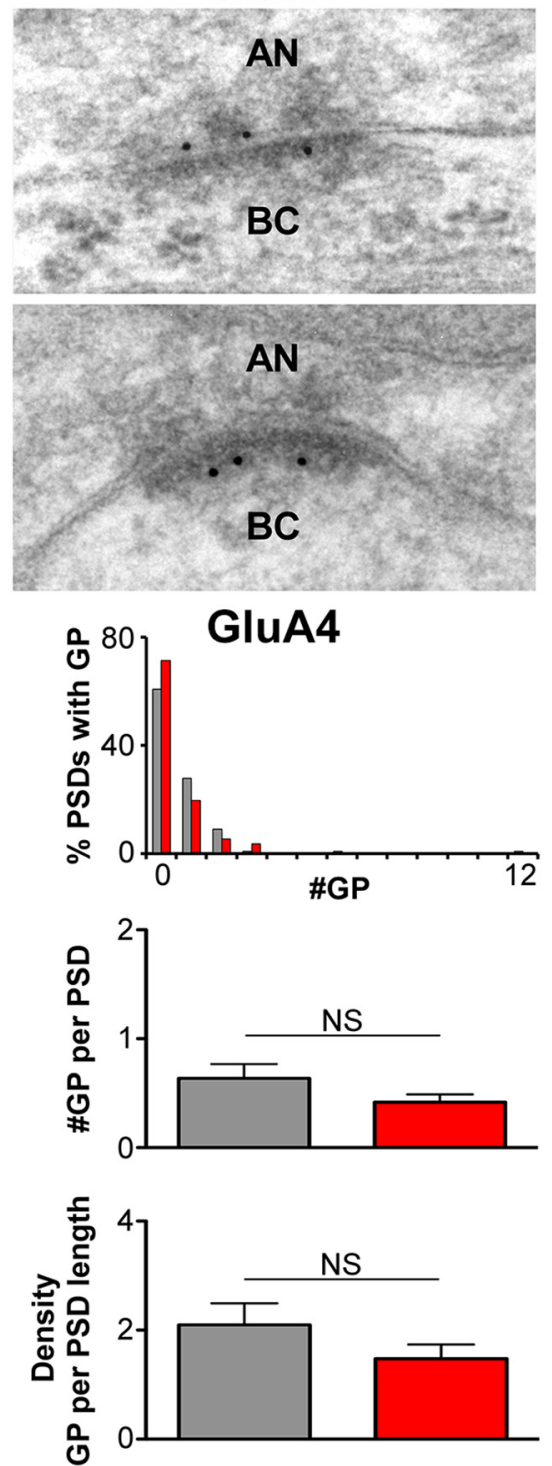

Figure 5. Monaural conductive hearing loss increases GluA3 AMPAR subunits at the synapse of the auditory nerve on bushy cells. $\boldsymbol{A}$, Examples of high-magnification electron micrographs of auditory nerve synapses on bushy cells that were immunogold labeled (10-nm-diameter gold particles) for GluA2/3, GluA2, and GluA4 from sham and earplugged animals at P40. AN, Auditory nerve; BC, bushy cell. Scale bar, $50 \mathrm{~nm}$. B, Distribution of GluA2/3, GluA2, and GluA4 gold particles per PSD of the synapse of the auditory nerve on bushy cells from sham and earplugged (EP) animals. GluA2/3 labeled/total \#PSD: sham, 125/155; EP, 125/144; GluA2 labeled/total \#PSD: sham, 48/112; EP, 46/106; GluA4 labeled/total \#PSD: sham, 44/112; EP, 32/112. C, Plots of the mean number and density of gold particles showing that GluA2/3 gold labeling was increased in earplugged (EP) animals (number: sham, 3.21 \pm 0.23 ; EP, $3.80 \pm 0.21 ; p=0.0132$, Mann-Whitney $U$ test; density: sham, $12.52 \pm 0.66 ; E P, 10.51 \pm 0.68 ; p=0.0122$, Mann-Whitney $U$ test). Gold labeling for GluA2 and GluA4 was similar between sham and EP animals (GluA2 number: sham, $0.61 \pm 0.08 ; \mathrm{EP}, 0.68 \pm 0.11 ; p=0.8389$, Mann-Whitney $U$ test; density: sham, $2.05 \pm 0.26 ; E P, 2.29 \pm 0.35 ; p=0.9374$, Mann-Whitney U test; GluA4 number: sham, $0.64 \pm 0.13 ; \mathrm{EP}, 0.42 \pm 0.07 ; p=0.1690$, Mann-Whitney $U$ test; density: sham, $2.1 \pm 0.40 ; \mathrm{EP}, 1.47 \pm 0.26 ; p=0.1603$, Mann-Whitney $U$ test). Error bars are \pm SEM. \#GP, Number of gold particles per PSD.

analysis of the number and density of gold particles per PSD revealed that GluA2/3 gold labeling remained significantly increased (number: $U=12,589 ; p=0.0002$, Mann-Whitney $U$ test; density: $U=12,301 ; p<0.0001$, Mann-Whitney U test; Fig. $6 C)$, whereas GluA2 gold labeling decreased compared with the age-matched sham group (number: $U=11,954 ; p=0.0008$, Mann-Whitney $U$ test; density: $U=11,630$; $p=0.0002$, MannWhitney $U$ test). No differences were observed in the number and density of GluA4 gold particles per PSD between the two animal groups at P50 (number: $U=14,340 ; p=0.5455$, Mann-Whitney $U$ test; density: $U=14,233$; $p=0.4619$, Mann-Whitney $U$ test; Fig. $6 C$ ). Within the shams group, the average number and den- sity for GluA2/3, GluA2, and GluA4 was similar between P40 and P50 shams ( $p>0.5$, Mann-Whitney $U$ test). Altogether, these results indicate that AMPAR subunit expression levels at the endbulb synapse do not return to preplugging levels even $10 \mathrm{~d}$ after earplug removal. Because of the decrease in GluA2 gold labeling alongside unchanged GluA4 labeling, the observed increase in GluA2/3 indicates that GluA3 was the primary AMPAR subunit at endbulb synapses after earplug removal. The high gold labeling for GluA3 subunits once sound levels are restored after earplug removal is not expected and suggests the absence of homeostatic mechanisms at endbulb synapses after transient sound deprivation. 
A
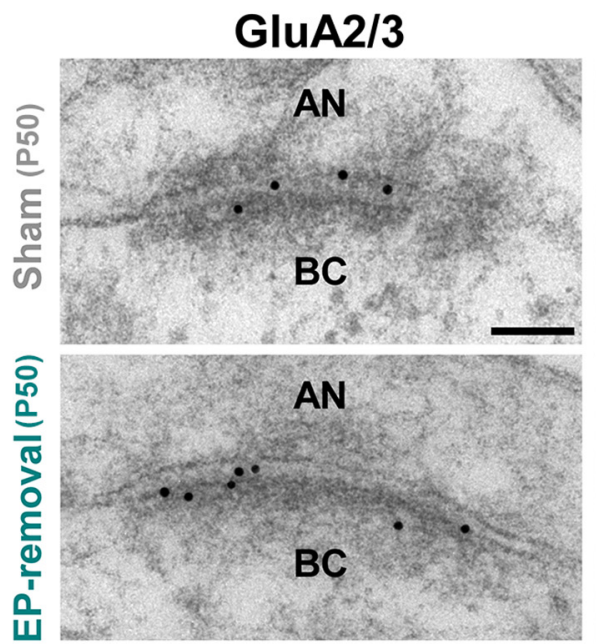

B

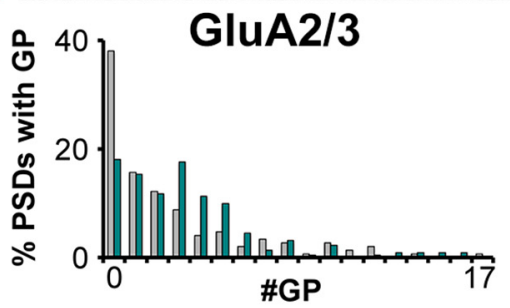

C
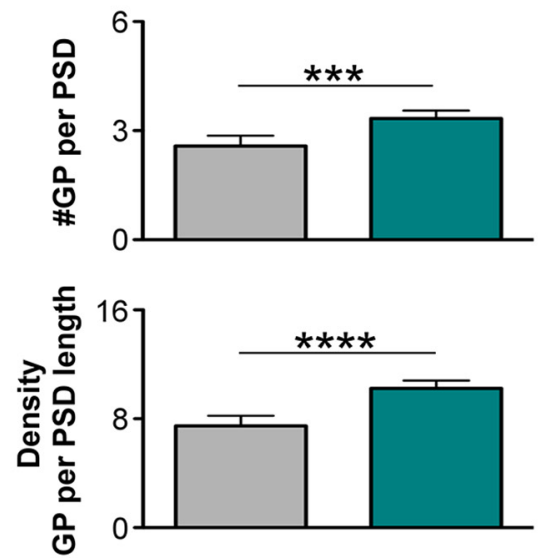

GluA2
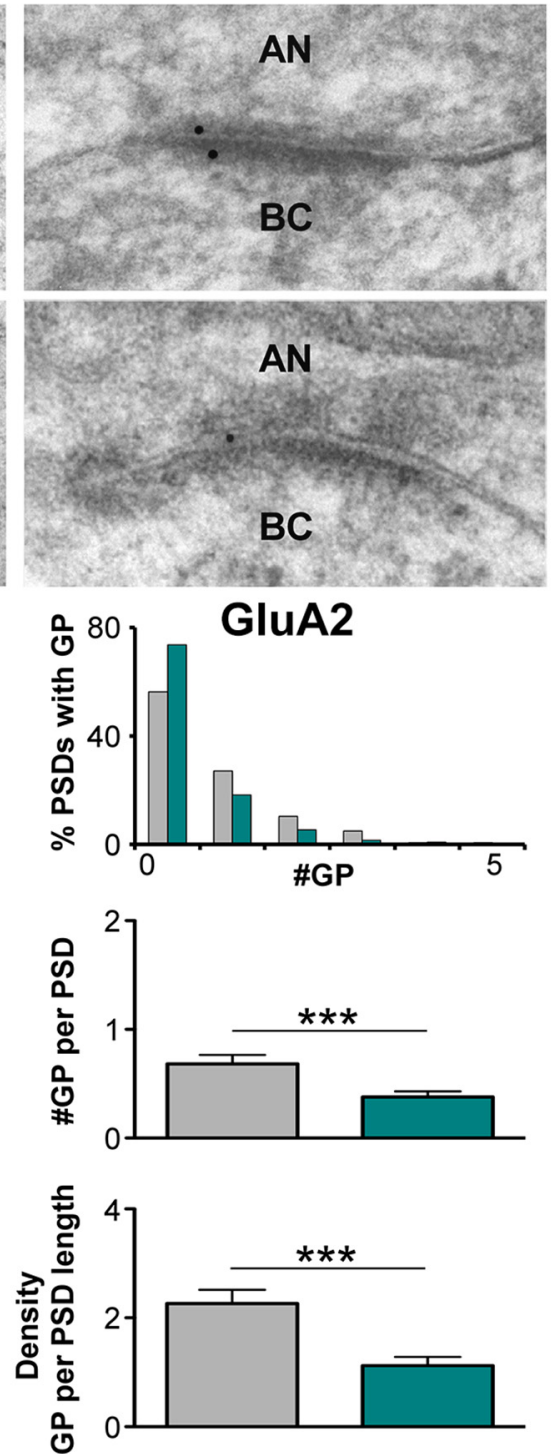

GluA4
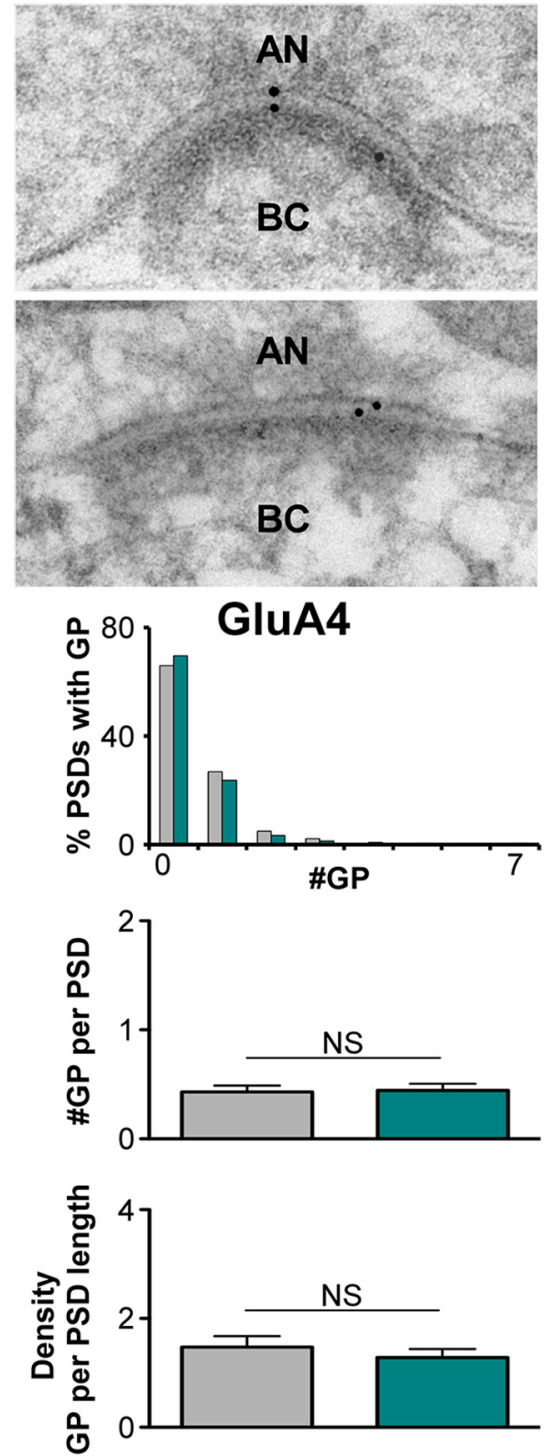

Figure 6. Redistribution of GluA2 and GluA3 AMPAR subunits at the synapse of the auditory nerve on bushy cells after earplug removal. $\boldsymbol{A}$, Examples of high-magnification electron micrographs of auditory nerve synapses on bushy cells that were immunogold labeled (10-nm-diameter gold particles) for GluA2/3, GluA2, and GluA4 from sham and earplug-removal groups at P50. AN, Auditory nerve; BC, bushy cells. Scale bar, $50 \mathrm{~nm}$. B , Distribution of gold particles for GluA2/3, GluA2, and GluA4 per PSD of auditory nerve synapses on bushy cells from sham and earplug-removal animals (GluA2/3 labeled/total \#PSD: sham, 89/145; earplug-removal, 178/218; GluA2 labeled/total \#PSD: sham, 61/142; earplug-removal, 52/199; GluA4 labeled/total \#PSD: sham, 47/139; earplugremoval, 63/207). C, Plots of the mean number and density of GluA2/3, GluA2, and GluA4 gold particles at the synapse of the auditory nerve on bushy cells from earplug-removal animals and age-matched shams. There was a significant increase in GluA2/3 gold particles (sham, $2.60 \pm 0.28$; earplug-removal, 3.33 $\pm 0.22 ; p=0.0002$, Mann-Whitney $U$ test) and a significant decrease in GluA2 gold particles (sham, $0.68 \pm 0.08$; earplug-removal, $0.37 \pm 0.05 ; p=0.0008$, Mann-Whitney $U$ test) in the earplug-removal group compared with the sham group. The gold labeling for GluA4 was similar between groups (sham, $0.43 \pm 0.05$; earplug-removal, $1.28 \pm 0.06 ; p=0.5455$, Mann-Whitney $U$ test). Error bars are $\pm S E M$. The density of gold particles for GluA2/3 was increased after earplug removal (sham, $7.40 \pm 0.75$; earplug-removal, $10.24 \pm 0.46 ; p<0.0001$, Mann-Whitney U test), whereas there was a significant decrease in GluA2 density (sham, $2.26 \pm$ 0.25 ; earplug-removal, $1.12 \pm 0.16 ; p=0.0002$, Mann-Whitney $U$ test). The density of GluA4 gold particles was similar between groups (sham, $1.47 \pm 0.20 ;$ earplug-removal, $1.28 \pm 0.16 ; p=$ 0.4619 , Mann-Whitney $U$ test). Error bars are \pm SEM. \#GP, Number of gold particles per PSD.

\section{Discussion}

Conductive hearing loss is the second most prevalent form of hearing loss, but its effects on central synapses have received relatively little attention. Auditory deprivation modifies auditory perception and physiology (Fournier et al., 2014). Psychoacoustics studies in adult humans with conductive hearing loss indicated plastic changes in the auditory brainstem as evidenced by changes in the threshold of an acoustic reflex, suggesting the existence of a gain mechanism operating at the level of the auditory brainstem (Munro and Blount, 2009). Our study shows that monaural conductive hearing loss (an; $40 \mathrm{~dB}$ SPL sound attenu- ation) in young adult rats leads to functional changes that persist after earplug removal and a recovery period of $10 \mathrm{~d}$. Although wave amplitudes measured at $10 \mathrm{~dB}$ SPL above thresholds were not affected by earplugging and peak latencies were reversed to age-matched sham levels, the hearing thresholds in response to clicks and middle to high frequencies $(16-32 \mathrm{kHz})$ were not recovered.

This increase in thresholds after a transient period of sound deprivation is consistent with studies performed in humans (Formby et al., 2003, 2007; Munro and Blount, 2009). Transient bilateral sound deprivation in gerbils (earplugging from P23 to 
P35), followed by a recovery period, does not impair auditory perception (Caras and Sanes, 2015). However, as occurs in the visual system, the effects of bilateral deprivation can be distinct from those because of monaural deprivation (Hutson et al., 2007). Therefore, the increase in thresholds found in our study could be behaviorally relevant during the recovery period or, alternatively, when animals are exposed to a noisy environment during that period. Altogether, our results show long-lasting presynaptic and postsynaptic structural and molecular effects at the endbulb of the Held synapse. Thus, we provide evidence for plasticity at the endbulb of Held synapses in the young adult in response to transient sound deprivation. However, this plasticity leads to an abnormal increase in the central gain within the lower auditory brainstem that may be involved in hyperacusis (for review, see Noreña, 2011).

\section{Regulation of endbulb synapses in response to monaural conductive hearing loss}

Monaural earplugging led to a decrease in SV size and a decrease in vGluT1 gold labeling. vGluT1 expression levels determine both the amount of glutamate loaded into vesicles and the amount of glutamate that is released (Wojcik et al., 2004; Wilson et al., 2005). It is still unclear whether the number of vesicular glutamate transporter molecules per SV directly correlates with the size of SVs. However, it was recently shown that vGluT1 function generates the tonicity of glutamatergic SVs, suggesting an effect on SV shape, and influences the stability of SVs in presynaptic terminals (Siksou et al., 2013). Furthermore, an in vivo study has shown that zebrafish glutamate transporter mutants have impaired presynaptic release of glutamate (decreased mEPSC amplitude) attributable to reduced vesicular glutamate uptake (Smear et al., 2007). Therefore, during earplugging, synaptic transmission can be compromised as vGluT1 is the main vesicular glutamate transporter in the endbulb terminals (Zhou et al., 2007; Gómez-Nieto and Rubio, 2009). As a result of the decrease in vGluT1 and smaller SVs, there will be lower levels of luminal glutamate in SVs and, consequently, a decrease in glutamate release at the cleft of the endbulb synapse. In response to reduced cleft glutamate by conductive hearing loss, postsynaptic homeostatic mechanisms, such as increased glutamate receptors and subsequent increased PSD size, may occur at the endbulb synapse. Certainly, we show an increase of the GluA3 AMPAR subunit together with thicker PSDs in animals that were earplugged for $10 \mathrm{~d}$. Based on our finding of an increased expression of AMPAR-GluA3 at the endbulb synapse, it is probable that monaural conductive hearing loss leads to a potentiation of synaptic responses. The potentiation of endbulb synapses through the upregulation of GluA3 might represent a compensatory mechanism to the reduction of auditory nerve activity by conductive hearing loss. A recent study demonstrated that sound-induced trauma slows AMPAR mediated excitatory synaptic current decay times by increasing GluA1 and decreasing GluA4 in the lateral superior olive (Pilati et al., 2016). The increased excitatory charge transfer caused by the slower current decay times boosted the compromised excitatory pathway, presumably enabling audible stimuli to provide a stronger excitatory input than in a normal animal (Pilati et al., 2016). The physiological consequences of an increase of the GluA3 subunit for synaptic transmission in the cochlear nucleus need further investigations, but it could well be that the decay times of excitatory currents are slower in
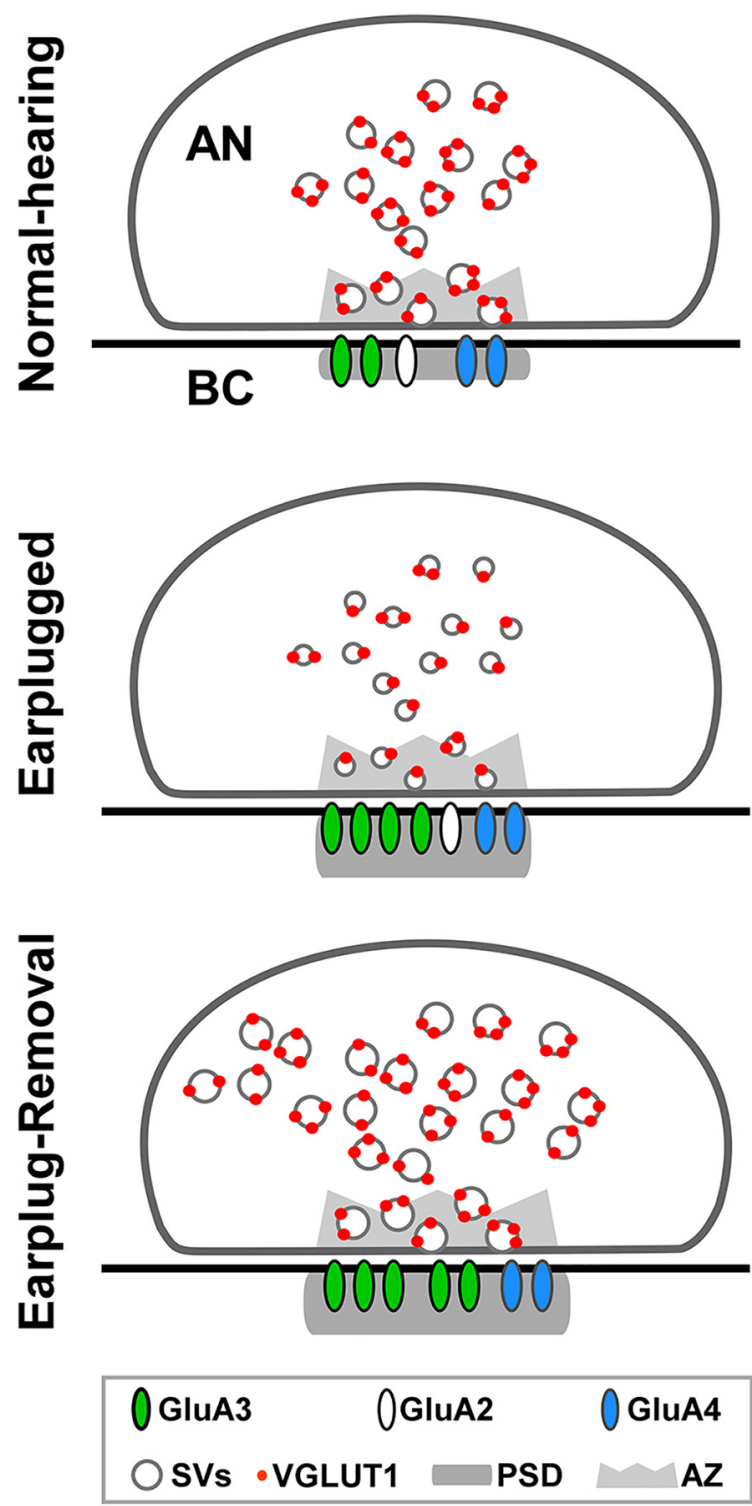

Figure 7. Diagram summary of the data obtained in this study. After $10 \mathrm{~d}$ of earplugging, there was a decrease in vGluT1 labeling at auditory nerve (AN) endings and in the size of SVs Postsynaptically, the PSDs of the AN on bushy cell (BC) somata were thicker and contained increased GluA3 AMPAR subunits. Ten days after earplug removal, there was an increase in the density of SVs in the AN; SVs were also larger in size. On BCs, the PSD apposed to the AN were larger and thicker, and they contained fewer GluA2 but more GluA3 subunits.

response to earplugging. This can happen, for example, if the ratio of GluA3 flip/flop isoforms is higher at the endbulb synapse in earplugged animals (Mosbacher et al., 1994; Gardner et al., 2001). This could provide a stronger excitatory input that will compensate for the reduction in sensory input. Additionally, our data show a gain increase in the average wave II/I ratio during earplugging in relation to control animals. Independent of whether monaural conductive hearing loss is short (1 d; Whiting et al., 2009) or long (10 d; present study), the GluA3 AMPAR subunit increases at the endbulb synapse in response to a decrease in sound levels. Thus, our results indicate that auditory experience-dependent adult plasticity of endbulb synapses is mediated specifically by regulation of GluA3 subunits. 


\section{Long-lasting effects on presynaptic and postsynaptic structures of endbulb synapses and GluA3 expression after earplug removal}

The functional changes observed in the present study after $10 \mathrm{~d}$ of monaural conductive hearing loss in young adult rats and a recovery period of another $10 \mathrm{~d}$ were paralleled by structural and molecular presynaptic and postsynaptic changes at the level of the endbulb synapse in the cochlear nucleus.

After earplug removal, we found in the endbulb terminals that vGluT1 gold labeling per SV recovered to sham levels. However, endbulb terminals had more SVs that were also larger. These findings suggest an increase in cleft glutamate because SVs are bigger and should thus have more glutamate molecules (Daniels et al., 2006). Nevertheless, an increase in cleft glutamate after earplug removal does not necessarily indicate more glutamate receptor activation because of the fast deactivation and desensitization of GluA3/4 AMPARs at the endbulb synapse (Gardner et al., 1999; Chanda and Xu-Friedman, 2010). Therefore, the putative increase in cleft glutamate may not translate into larger EPSCs (Vasileva et al., 2012). Hypothetically, an increase in glutamate in the synaptic cleft could have led to a decrease in the number of AMPARs in the PSD, as a way to compensate for the excess of glutamate in the cleft. However, GluA3 subunit labeling was increased in response to conductive hearing loss after the recovery period. The increase in glutamate together with an increase in AMPARs can also, but not necessarily, potentiate synaptic transmission in the endbulb terminal. Additional evidence arguing in favor of an increase in cleft glutamate after earplug removal was the larger and thicker PSDs of endbulb synapses compared with sham-treated animals. Endbulb synapses of congenital deaf cats and mice have hypertrophied PSDs (Ryugo et al., 1997; Lee et al., 2003), but the hypertrophied PSDs resemble those of normal hearing cats after sound stimulation (Ryugo et al., 2005), indicating that auditory nerve synaptic activity influences the size of the synapse. We can speculate that larger PSDs and more GluA3 AMPARs will likely make this synapse less resilient and more vulnerable to changes in environmental sound levels. Thus, our results suggest that normal auditory nerve function, which is important for the transmission of fine timing information that is necessary for sound localization (Yang and Xu-Friedman, 2009), is likely affected after conductive hearing loss. Moreover, our finding that an increase in gain at the level of the lateral lemniscus persists after sound levels are restored suggests long-lasting changes that can compromise auditory processing beyond the cochlear nucleus after conductive hearing loss.

\section{Plasticity at the endbulb of Held synapse in response to conductive hearing loss}

Most of the studies addressing plasticity in the adult (P30 and beyond) have been performed in the barrel or visual cortices. For example, the barrel cortex receptive fields can be altered by experience in adult rats (Polley et al., 2004; Rema et al., 2006); dendritic spines, which are considered to be the morphological correlates of experience-dependent synaptic plasticity, continue to turn over in adults in both the visual and somatosensory cortices (Zuo et al., 2005; Holtmaat et al., 2006). Manipulation of in vivo sensory experience also produces homeostatic changes at cortical synapses. Depriving vision from 2 to up to $7 \mathrm{~d}$ scales up excitatory synapses in the visual cortex pyramidal neurons, by incorporating more GluA1 AMPAR subunits, whereas reexposing the visually deprived animals to light scales down the synapses (Goel et al., 2006, 2011; Goel and Lee, 2007). Interestingly, the sensory experience-induced homeostatic synaptic changes are mainly observed as regulation of the amplitude rather than the frequency of AMPA-mEPSCs. This suggests that in vivo sensory experience-dependent changes in the cortex are mainly postsynaptic in nature at the level of AMPAR regulation (Goel and Lee, 2007; Lee, 2012). Overall, our study shows in P30 rats, once past maturation of connectivity and synaptic elements in the cochlear nucleus, that earplugging sets in motion complex changes that may ultimately lead to increases in synaptic strength at endbulb synapses through presynaptic and postsynaptic mechanisms (Fig. 7). At $10 \mathrm{~d}$ of earplugging, vGluT1 expression levels at endbulb endings decreased and synaptic vesicles were smaller; postsynaptically, the PSD was thicker and contained more GluA3. After $10 \mathrm{~d}$ of earplug removal, vGluT1 expression recovered, but synaptic vesicles were larger compared with both shams and $10 \mathrm{~d}$ of earplugging. At the postsynaptic levels, the PSD became enlarged in size and thickness and contained more GluA3 AMPA receptor subunits. It is striking that some of these changes, such as the increase in GluA3 and PSD thickness, continue after earplug removal. Other changes begin after earplug removal and do not reverse, e.g., GluA2 removal and rebound enhancement of SV size and density. The rebound effect is surprising and contrasts with a simpler "homeostatic plasticity" concept (for review, see Nelson and Turrigiano, 2008). Our findings show that sensory-dependent evoked plasticity is more complex than what might be predicted from experiments in reduced systems. Future studies could investigate in the adult long-term hearing sensitivities after conductive hearing loss in chronic otitis media with effusion, which is prevalent in children. Such studies will settle the central mechanisms of deficits in auditory perception, language acquisition, or educational disabilities that occur after inadequate or abnormal sensory experience.

\section{References}

Allen CB, Celikel T, Feldman DE (2003) Long-term depression induced by sensory deprivation during cortical map plasticity in vivo. Nat Neurosci 6:291-299. CrossRef Medline

Asako M, Holt AG, Griffith RD, Buras ED, Altschuler RA (2005) Deafnessrelated decreases in glycine-immunoreactive labeling in the rat cochlear nucleus. J Neurosci Res 81:102-109. CrossRef Medline

Bender KJ, Allen CB, Bender VA, Feldman DE (2006) Synaptic basis for whisker deprivation-induced synaptic depression in rat somatosensory cortex. J Neurosci 26:4155-4165. CrossRef Medline

Bredt DS, Nicoll RA (2003) AMPA receptor trafficking at excitatory synapses. Neuron 40:361-379. CrossRef Medline

Caras ML, Sanes DH (2015) Sustained perceptual deficits from transient sensory deprivation. J Neurosci 35:10831-10842.

Chanda S, Xu-Friedman MA (2010) A low-affinity antagonist reveals saturation and desensitization in mature synapses in the auditory brain stem. J Neurophysiol 103:1915-1926. CrossRef Medline

Coleman JE, Nahmani M, Gavornik JP, Haslinger R, Heynen AJ, Erisir A, Bear MF (2010) Rapid structural remodeling of thalamocortical synapses parallels experience-dependent functional plasticity in mouse primary visual cortex. J Neurosci 30:9670-9682. CrossRef Medline

Collingridge GL, Isaac JT, Wang YT (2004) Receptor trafficking and synaptic plasticity. Nat Rev Neurosci 5:952-962. CrossRef Medline

Cook RD, Hung TY, Miller RL, Smith DW, Tucci DL (2002) Effects of conductive hearing loss on auditory nerve activity in gerbil. Hear Res 164: 127-137.

Daniels RW, Collins CA, Chen K, Gelfand MV, Featherstone DE, DiAntonio A (2006) A single vesicular glutamate transporter is sufficient to fill a synaptic vesicle. Neuron 49:11-16. CrossRef Medline

Deerinck TJ, Bushong EA, Thor A, Ellisman MH (2010) A new protocol for preparation of biological specimens for serial block face scanning electron microscopy. Microsc Microanal 16 [Suppl 2]:1138-1139. CrossRef

Dosemeci A, Tao-Cheng JH, Vinade L, Winters CA, Pozzo-Miller L, Reese TS (2001) Glutamate-induced transient modification of the postsynaptic density. Proc Natl Acad Sci U S A 98:10428-10432. CrossRef Medline 
Erickson JD, De Gois S, Varoqui H, Schafer MK, Weihe E (2006) Activitydependent regulation of vesicular glutamate and GABA transporters: a means to scale quantal size. Neurochem Int 48:643-649. CrossRef Medline

Fiala JC (2005) Reconstruct: a free editor for serial section microscopy. J Microsc 218:52-61. CrossRef Medline

Ferguson MO, Cook RD, Hall JW 3rd, Grose JH, Pillsbury HC 3rd (1998) Chronic conductive hearing loss in adults: effects on the auditory brainstem response and masking-level difference. Arch Otolaryngol Head Neck Surg 124:678-685.

Formby C, Sherlock LP, Gold SL (2003) Adaptive plasticity of loudness induced by chronic attenuation and enhancement of the acoustic background. J Acoust Soc Am 114:55-58. CrossRef Medline

Formby C, Sherlock LP, Gold SL, Haweley ML (2007) Adaptive recalibration of central auditory gain. Semin Hear 28:295-302.

Fournier P, Schönwiesner M, Hébert S (2014) Loudness modulation after transient and permanent hearing loss: implications for tinnitus and hyperacusis. Neuroscience 283:64-77. CrossRef Medline

Fyk-Kolodziej B, Shimano T, Gong TW, Holt AG (2011) Vesicular glutamate transporters: spatio-temporal plasticity following hearing loss. Neuroscience 178:218-239. CrossRef Medline

Gardner SM, Trussell LO, Oertel D (1999) Time course and permeation of synaptic AMPA receptors in cochlear nuclear neurons correlate with input. J Neurosci 19:8721-8729. Medline

Gardner SM, Trussell LO, Oertel D (2001) Correlation of AMPA receptor subunit composition with synaptic input in the mammalian cochlear nuclei. J Neurosci 21:7428-7437. Medline

Goel A, Lee HK (2007) Persistence of experience-induced homeostatic synaptic plasticity through adulthood in superficial layers of mouse visual cortex. J Neurosci 27:6692-6700. CrossRef Medline

Goel A, Jiang B, Xu LW, Song L, Kirkwood A, Lee HK (2006) Cross-modal regulation of synaptic AMPA receptors in primary sensory cortices by visual experience. Nat Neurosci 9:1001-1003. CrossRef Medline

Goel A, Xu LW, Snyder KP, Song L, Goenaga-Vazquez Y, Megill A, Takamiya K, Huganir RL, Lee HK (2011) Phosphorylation of AMPA receptors is required for sensory deprivation-induced homeostatic synaptic plasticity. PLoS One 6:e18264. CrossRef Medline

Gómez-Nieto R, Rubio ME (2009) A bushy cell network in the rat ventral cochlear nucleus. J Comp Neurol 516:241-263. CrossRef Medline

Gulley RL, Wenthold RJ, Neises GR (1977) Remodeling of neuronal membranes as an early response to deafferentation. A freeze-fracture study. J Cell Biol 75:837-850. CrossRef Medline

Hofer SB, Mrsic-Flogel TD, Bonhoeffer T, Hübener M (2009) Experience leaves a lasting structural trace in cortical circuits. Nature 457:313-317. CrossRef Medline

Hollmann M, Heinemann S (1994) Cloned glutamate receptors. Annu Rev Neurosci 17:31-108. CrossRef Medline

Holtmaat A, Wilbrecht L, Knott GW, Welker E, Svoboda K (2006) Experience-dependent and cell-type-specific spine growth in the neocortex. Nature 441:979-983. CrossRef Medline

Hutson KA, Durham D, Tucci DL (2007) Consequences of unilateral hearing loss: time dependent regulation of protein synthesis in auditory brainstem nuclei. Hear Res 233:124-134. CrossRef Medline

Ito T, Bishop DC, Oliver DL (2011) Expression of glutamate and inhibitory amino acid vesicular transporters in the rodent auditory brainstem. J Comp Neurol 519:316-3140. CrossRef Medline

Joris PX, Carney LH, Smith PH, Yin TC (1994) Enhancement of neural synchronization in the anteroventral cochlear nucleus. I. Responses to tones at the characteristic frequency. J Neurophysiol 71:1022-1036. Medline

Karunanithi S, Marin L, Wong K, Atwood HL (2002) Quantal size and variation determined by vesicle size in normal and mutant Drosophila glutamatergic synapses. J Neurosci 22:10267-10276. Medline

Lee DJ, Cahill HB, Ryugo DK (2003) Effects of congenital deafness in the cochlear nuclei of Shaker-2 mice: an ultrastructural analysis of synapse morphology in the endbulbs of Held. J Neurocytol 32:229-243. CrossRef Medline

Lee HK (2012) Ca2 + permeable AMPA receptors in homeostatic synaptic plasticity. Front Mol Neruosci 5:1-11.

Li P, Rudolph U, Huntsman MM (2009) Long-term sensory deprivation selectively rearranges functional inhibitory circuits in mouse barrel cortex. Proc Natl Acad Sci U S A 106:12156-12161. CrossRef Medline

Liguz-Lecznar M, Skangiel-Kramska J (2007) Vesicular glutamate trans- porters (VGLUTs): the three musketeers of glutamatergic system. Acta Neurobiol Exp (Wars) 67:207-218. Medline

Maffei A, Nelson SB, Turrigiano GG (2004) Selective reconfiguration of layer 4 visual cortical circuitry by visual deprivation. Nat Neurosci 7:1353-1359. CrossRef

McGinn MD, Henry KR (1975) Acute versus chronic acoustic deprivation: effects on auditory evoked potentials and seizures in mice. Dev Psychobiol 8:223-232. CrossRef Medline

Mosbacher J, Schoepfer R, Monyer H, Burnashev N, Seeburg PH, Ruppersberg JP (1994) A molecular determinant for millisecond desensitization in glutamate receptors. Science 266:1059-1062. CrossRef Medline

Munro KJ, Blount J (2009) Adaptive plasticity in brainstem of adult listeners following earplug-induced deprivation. J Acoust Soc Am 126: 568-571. CrossRef Medline

Nelson SB, Turrigiano GG (2008) Strength through diversity. Neuron 60: 477-482. CrossRef Medline

Noreña AJ (2011) An integrative model of tinnitus based on a central gain controlling neuronal sensitivity. Neurosci Biobehav Rev 35:1089-1109. CrossRef Medline

Oleskevich S, Walmsley B (2002) Synaptic transmission in the auditory brainstem of normal and congenitally deaf mice. J Physiol 540:447-455. Medline

Parsons TD, Coorssen JR, Horstmann H, Almers W (1995) Docked granules, the exocytic burst, and the need for ATP hydrolysis in endocrine cells. Neuron 15:1085-1096. CrossRef Medline

Pilati N, Linley DM, Selvaskandan H, Uchitel O, Hennig MH, KoppScheinpflug C, Forsythe ID (2016) Acoustic trauma slows AMPA receptor-mediated EPSCs in the auditory brainstem, reducing GluA4 subunit expression as a mechanism to rescue binaural function. J Physiol 594:3683-3703. CrossRef Medline

Polley D, Kvasnak E, Frostig RD (2004) Naturalistic experience transforms sensory maps in the adult cortex of caged animals. Nature 429:67-71. CrossRef Medline

Popescu MV, Polley DB (2010) Monaural deprivation disrupts development of binaural selectivity in auditory midbrain and cortex. Neuron 65:718-731. CrossRef Medline

Potashner SJ, Suneja SK, Benson CG (1997) Regulation of D-aspartate release and uptake in adult brain stem auditory nuclei after unilateral middle ear ossicle removal and cochlear ablation. Exp Neurol 148:222-235.

Redd EE, Pongstaporn T, Ryugo DK (2000) The effects of congenital deafness on auditory nerve synapses and globular bushy cells in cats. Hear Res 147:160-174. CrossRef Medline

Rema V, Armstrong-James M, Jenkinson N, Ebner FF (2006) Short exposure to an enriched environment accelerates plasticity in the barrel cortex of adult rats. Neuroscience 140:659-672. CrossRef Medline

Rouiller EM, Cronin-Schreiber R, Fekete DM, Ryugo DK (1986) The central projections of intracellularly labeled auditory nerve fibers in cats: an analysis of terminal morphology. J Comp Neurol 249:261-278. CrossRef Medline

Rubio ME (2006) Redistribution of synaptic AMPA receptors at glutamatergic synapses in the dorsal cochlear nucleus as an early response to cochlear ablation in rats. Hear Res 216-217:154-167. CrossRef Medline

Rubio ME, Wenthold RJ (1997) Glutamate receptors are selectively targeted to postsynaptic sites in neurons. Neuron 18:939-950. CrossRef Medline

Rubio ME, Wenthold RJ (1999) Differential distribution of intracellular glutamate receptors in dendrites. J Neurosci 19:5549-5962. Medline

Rubio ME, Gudsnuk KA, Smith Y, Ryugo DK (2008) Revealing the molecular layer of the primate dorsal cochlear nucleus. Neuroscience 154: 99-113. CrossRef Medline

Ryugo DK, Fekete DM (1982) Morphology of primary axosomatic endings in the anteroventral cochlear nucleus of the cat: a study of the endbulbs of Held. J Comp Neurol 210:239-257. CrossRef Medline

Ryugo DK, Pongstaporn T, Huchton DM, Niparko JK (1997) Ultrastructural analysis of primary endings in deaf white cats: morphologic alterations in endbulbs of Held. J Comp Neurol 385:230-244. CrossRef Medline

Ryugo DK, Kretzmer EA, Niparko JK (2005) Restoration of auditory nerve synapses in cats by cochlear implants. Science 310:1490-1492. CrossRef Medline

Schaette R, McAlpine D (2011) Tinnitus with a normal audiogram: physiological evidence for hidden hearing loss and computational model. J Neurosci 31:13452-13457. CrossRef Medline 
Shaheen LA, Valero MD, Liberman MC (2015) Towards a diagnosis of cochlear neuropathy with envelope following responses. J Assoc Res Otolaryngol 16:727-745. CrossRef Medline

Sheng M, Hoogenraad CC (2007) The postsynaptic architecture of excitatory synapses: a more quantitative view. Annu Rev Biochem 76:823-847. CrossRef Medline

Siksou L, Slim K, Biesemann C, Nehring RB, Wojcik SM, Triller A, Mestikawy SE, Marty S, Herzog E (2013) A role for vesicular glutamate transporter 1 in synaptic vesicle clustering and mobility. Eur J Neurosci 37:16311642. CrossRef Medline

Smear MC, Tao HW, Staub W, Orger MB, Gosse NJ, Liu Y, Takahashi K, Poo MM, Baier H (2007) Vesicular glutamate transport at a central synapse limits the acuity of visual perception in zebrafish. Neuron 53:65-77. CrossRef Medline

Sumner CJ, Tucci DL, Shore SE (2005) Responses of the ventral cochlear nucleus to contralateral sound following conductive hearing loss. J Neurophysiol 94:4234-4243.

Suneja SK, Potashner SJ, Benson CG (1998) Plastic changes in glycine and GABA release and uptake in adult brain stem auditory nuclei after unilateral middle ear ossicle removal and cochlear ablation. Exp Neurol 151: 273-288. CrossRef Medline

Takesian AE, Kotak VC, Sanes DH (2012) Age-dependent effect of hearing loss on cortical inhibitory synapse function. J Neurophysiol 107:937-947. CrossRef Medline

Tucci DL, Cant NB, Durham D (1999) Conductive hearing loss results in a decrease in central auditory system activity in the young gerbil. Laryngoscope 109:1359-1371.

Tucci DL, Cant NB, Durham D (2001) Effects of conductive hearing loss on gerbil central auditory system activity in silence. Hear Res 155:124-132.

Tucci DL, Cant NB, Durham D (2002) Conductive hearing loss results in changes in cytochrome oxidase activity in gerbil central auditory system. J Assoc Res Otolaryngol 3:89-106.

Vasileva M, Horstmann H, Geumann C, Gitler D, Kuner T (2012) Synapsin-dependent reserve pool of synaptic vesicles supports replenishment of the readily releasable pool under intense synaptic transmission. Eur J Neurosci 36:3005-3020. CrossRef Medline

Walton J (1979) Lead aspartate, an en bloc contrast stain particularly useful for ultrastructural enzymology. J Histochem Cytochem 27:1337-1342.

Wang H, Yin G, Rogers K, Miralles C, De Blas AL, Rubio ME (2011) Monaural conductive hearing loss alters the expression of the GluA3 AMPA and glycine receptor $\alpha 1$ subunits in bushy and fusiform cells of the cochlear nucleus. Neuroscience 199:438-451. CrossRef Medline
Wang Y, Manis PB (2005) Synaptic transmission at the cochlear nucleus endbulb synapse during age-related hearing loss in mice. J Neurophysiol 94:1814-1824. CrossRef Medline

Wang Y, Manis PB (2006) Temporal coding by cochlear nucleus bushy cells in DBA/2J mice with early onset hearing loss. J Assoc Res Otolaryngol 7:412-424. CrossRef Medline

Wang YX, Wenthold RJ, Ottersen OP, Petralia RS (1998) Endbulb synapses in the anteroventral cochlear nucleus express a specific subset of AMPAtype glutamate receptor subunits. J Neurosci 18:1148-1160. Medline

Whiting B, Moiseff A, Rubio ME (2009) Cochlear nucleus neurons redistribute synaptic AMPA and glycine receptors in response to monaural conductive hearing loss. Neuroscience 163:1264-1276. CrossRef Medline

Wilson NR, Kang J, Hueske EV, Leung T, Varoqui H, Murnick JG, Erickson JD, Liu G (2005) Presynaptic regulation of quantal size by the vesicular glutamate transporter VGLUT1. J Neurosci 25:6221-6234. CrossRef Medline

Wojcik SM, Rhee JS, Herzog E, Sigler A, Jahn R, Takamori S, Brose N, Rosenmund C (2004) An essential role for vesicular glutamate transporter 1 (VGLUT1) in postnatal development and control of quantal size. Proc Natl Acad Sci U S A 101:7158-7163. CrossRef Medline

Xu H, Kotak VC, Sanes DH (2007) Conductive hearing loss disrupts synaptic and spike adaptation in developing auditory cortex. J Neurosci 27: 9417-9426. CrossRef Medline

Xu H, Kotak VC, Sanes DH (2010) Normal hearing is required for the emergence of long-lasting inhibitory potentiation in cortex. J Neurosci 30: 331-341. CrossRef Medline

Yang H, Xu-Friedman MA (2009) Impact of synaptic depression on spike timing at the endbulb of Held. J Neurophysiol 102:1699-1710. CrossRef Medline

Zeng C, Nannapaneni N, Zhou J, Hughes LF, Shore S (2009) Cochlear damage changes the distribution of vesicular glutamate transporters associated with auditory and nonauditory inputs to the cochlear nucleus. J Neurosci 29:4210-4217. CrossRef Medline

Zhou J, Nannapaneni N, Shore S (2007) Vesicular glutamate transporters 1 and 2 are differentially associated with auditory nerve and spinal trigeminal inputs to the cochlear nucleus. J Comp Neurol 500:777-787. CrossRef Medline

Zuo Y, Yang G, Kwon E, Gan WB (2005) Long-term sensory deprivation prevents dendritic spine loss in primary somatosensory cortex. Nature 436:261-265. CrossRef Medline 